\title{
Mechanisms and Effects of Intracellular Calcium Buffering on Neuronal Survival in Organotypic Hippocampal Cultures Exposed to Anoxia/Aglycemia or to Excitotoxins
}

\author{
Khaled M. Abdel-Hamid ${ }^{1}$ and Michael Tymianski ${ }^{1,2}$ \\ ${ }^{1}$ Playfair Neuroscience Unit and ${ }^{2}$ Division of Neurosurgery, University of Toronto, Toronto, Ontario M5T-2S8, Canada
}

Neuronal calcium loading attributable to hypoxic/ischemic injury is believed to trigger neurotoxicity. We examined in organotypic hippocampal slice cultures whether artificially and reversibly enhancing the $\mathrm{Ca}^{2+}$ buffering capacity of neurons reduces the neurotoxic sequelae of oxygen-glucose deprivation (OGD), whether such manipulation has neurotoxic potential, and whether the mechanism underlying these effects is preor postsynaptic. Neurodegeneration caused over 24 hr by 60 min of OGD was triggered largely by NMDA receptor activation and was attenuated temporarily by pretreating the slices with cell-permeant $\mathrm{Ca}^{2+}$ buffers such as 1,2 bis(2aminophenoxy)ethane- $N, N, N^{\prime}, N^{\prime}$-tetra-acetic acid acetoxymethyl ester (BAPTA-AM). This pretreatment produced a transient, reversible increase in intracellular buffer content as demonstrated autoradiographically using slices loaded with ${ }^{14} \mathrm{C}-\mathrm{BAPTA}-\mathrm{AM}$ and by confocal imaging of slices loaded with the BAPTA-AM analog calcium green-acetoxymethyl ester (AM). The time courses of ${ }^{14} \mathrm{C}$-BAPTA retention and of neuronal survival after OGD were identical, indicating that increased buffer content is necessary for the observed protective effect. Protection by $\mathrm{Ca}^{2+}$ buffering originated presynaptically because BAPTA-AM was ineffective when endogenous transmitter release was bypassed by directly applying NMDA to the cultures, and because pretreatment with the low $\mathrm{Ca}^{2+}$ affinity buffer 2-aminophenol- $\mathrm{N}, \mathrm{N}, \mathrm{O}$-triacetic acid acetoxymethyl ester, which attenuates excitatory transmitter release, attenuated neurodegeneration. Thus, in cultured hippocampal slices, enhancing neuronal $\mathrm{Ca}^{2+}$ buffering unequivocally attenuates or delays the onset of anoxic neurodegeneration, likely by attenuating the synaptic release of endogenous excitatory neurotransmitters (excitotoxicity).

Key words: calcium; cell death; anoxia; calcium buffers; neurotoxicity; organotypic cultures; hippocampal neurons; BAPTA; oxygen-glucose deprivation; presynaptic mechanisms
Does increasing the ability of neurons to buffer calcium loads give them increased resilience to hypoxic/ischemic insults? This hypothesis is attractive because excessive $\mathrm{Ca}^{2+}$ loading has been shown repeatedly to trigger neurodegeneration (for review, see Choi, 1988; Ghosh and Greenberg, 1995; Tymianski, 1996; Tymianski and Tator, 1996). Because most (>95\%) $\mathrm{Ca}^{2+}$ ions that enter cells under physiological conditions are buffered by endogenous mechanisms (Blaustein, 1988; Neher and Augustine, 1992; Zhou and Neher, 1993), it is intuitive to assume that $\mathrm{Ca}^{2+}$ buffering ability may be related to neuronal vulnerability. However, the $\mathrm{Ca}^{2+}$ buffering machinery of neurons has been difficult to manipulate in order to experimentally test this hypothesis. Although immobile $\mathrm{Ca}^{2+}$ buffering sites such as mitochondria can be manipulated pharmacologically (Werth and Thayer, 1994; White and Reynolds, 1995; Budd and Nicholls, 1996a; Schindler et al., 1996), the mobile buffering component, composed primarily of $\mathrm{Ca}^{2+}$-binding proteins, cannot. Thus, most studies of relationships between endogenous mobile $\mathrm{Ca}^{2+}$ buffer content and neuronal survivability have been correlative in nature. Opinions arising from these are

Received Dec. 10, 1996; revised Feb. 18, 1997; accepted Feb. 25, 1997.

M.T. is a Clinician Scientist of the Medical Research Council of Canada. This work was supported by an Ontario Technology Fund Grant in collaboration with Allelix Biopharmaceuticals to M.T. We thank Lucy Teves for technical assistance.

Correspondence should be addressed to Dr. Michael Tymianski, Neuroprotection Laboratory, Lab 11-416, MC-PAV, Playfair Neuroscience Unit, Toronto Hospital, Western Division, 399 Bathurst Street, Toronto, Ontario M5T-2S8, Canada.

Copyright (C) 1997 Society for Neuroscience $0270-6474 / 97 / 173538-16 \$ 05.00 / 0$ divided on whether $\mathrm{Ca}^{2+}$ buffers are beneficial against injury. For example, neurons expressing calbindin- $\mathrm{D}_{28 \mathrm{~K}}$ or parvalbumin may be more resistant to damage produced by excitatory amino acids (EAAs) and other toxins in vitro (Scharfman and Schwartzkroin, 1989; Mattson et al., 1991; Lukas and Jones, 1994; Diop et al., 1995; Pike and Cotman, 1995) and ischemic damage in vivo (Nitsch et al., 1989; Rami et al., 1992; Goodman et al., 1993). However, some studies refute this or fail to show such correlations (Freund et al., 1990; Weiss et al., 1990; Freund and Magloczky, 1993; Mockel and Fischer, 1994; Tortosa and Ferrer, 1994).

Recently, it has been possible to manipulate intracellular calcium-binding proteins directly. Lledo et al. (1992) transfected GH3 cells with calbindin- $\mathrm{D}_{28 \mathrm{~K}}$, which attenuated $\mathrm{Ca}^{2+}$ currents and depolarization-evoked elevations in intracellular cytosolic $\mathrm{Ca}^{2+}$ concentration $\left(\left[\mathrm{Ca}^{2+}\right]_{\mathrm{i}}\right)$ transients. Chard et al. (1993) directly injected calbindin and parvalbumin into neurons via patch pipettes, which attenuated $\left[\mathrm{Ca}^{2+}\right]_{\mathrm{i}}$ increases in the cells. However, such experiments have not yet shown whether calcium-binding proteins subserve a neuroprotective function. A simpler alternative to manipulating endogenous $\mathrm{Ca}^{2+}$ buffers is to use synthetic, exogenous $\mathrm{Ca}^{2+}$ chelators (Tsien, 1980). The advantages over using $\mathrm{Ca}^{2+}$ binding proteins include a nondisruptive means to introduce the buffers into cells (Tsien, 1981), predictable $\mathrm{Ca}^{2+}$ buffering properties, and the potential for reversing their physiological actions through inactivation and/or cellular extrusion (Ouanounou et al., 1996). The physiological effects of exogenous buffers are well characterized, including their presynaptic effects 
on attenuating neurotransmitter release (Adler et al., 1991; Niesen et al., 1991; Fredholm and Hu, 1993; Roberts, 1993; Robitaille et al., 1993; Winslow et al., 1994; Ouanounou et al., 1996; Spigelman et al., 1996), postsynaptic effects on neuronal membrane excitability (Marty and Neher, 1985; Lancaster and Nicoll, 1987; Kohr and Mody, 1991; Schwindt et al., 1992; Zhang et al., 1995), and $\mathrm{Ca}^{2+}$ homeostasis (Neher, 1986; Neher and Augustine, 1992; Zhou and Neher, 1993; Tymianski et al., 1994a).

The utility of exogenous $\mathrm{Ca}^{2+}$ buffers as neuroprotectants against EAA excess has been examined previously, although with varying conclusions (Tymianski et al., 1993c, 1994a; but see Baimbridge and Abdel-Hamid, 1992; Dubinsky, 1993; Abdel-Hamid, 1994). However, their effects against anoxic neuronal injury have never been systematically explored, despite the fact that synaptic overactivity, which is attenuated by these compounds (see references above), is believed to be an etiological factor in anoxia (Kass and Lipton, 1982; Rothman, 1983, 1984). Also, although the many physiological effects of $\mathrm{Ca}^{2+}$ buffers on both presynaptic and postsynaptic $\mathrm{Ca}^{2+}$-dependent processes are described (see references above), the effects specifically responsible for their neuroprotective properties have not been established.

Therefore, we studied for the first time the effects of $\mathrm{Ca}^{2+}$ buffering on anoxic neurodegeneration. We examined whether artificially and reversibly enhancing the $\mathrm{Ca}^{2+}$ buffering capacity of neurons reduces the neurotoxic sequelae of oxygen-glucose deprivation (OGD), whether such manipulation has neurotoxic potential, and whether the mechanism underlying these effects is pre- or postsynaptic. We show unequivocally, using novel means, that neuroprotection in organotypic hippocampal slice cultures parallels exactly alterations in $\mathrm{Ca}^{2+}$ buffer content, that in select circumstances cell-permeant $\mathrm{Ca}^{2+}$ buffers also have neurotoxic potential, and that the site of neuroprotective actions of exogenous buffers is presynaptic, indicating that neuroprotection is achieved chiefly by attenuation of excitatory neurotransmitter release.

\section{MATERIALS AND METHODS}

Preparation of organotypic cultures. Organotypic hippocampal slice cultures were prepared according to the method of Stoppini et al. (1991) with minor modifications. Briefly, $7 \mathrm{~d}$ postnatal Wistar rat pups were anesthetized $(50 \mathrm{mg} / \mathrm{kg}$ ketamine, i.p.), decapitated, and the hippocampi were removed and incubated (5 min) in ice-cold HBSS supplemented with D-glucose (to $6.5 \mathrm{mg} / \mathrm{ml}$ ) and $20 \mathrm{mM}$ HEPES acid/HEPES sodium salt, $\mathrm{pH}$ 7.2. Transverse hippocampal slices $(400 \mu \mathrm{m})$ were obtained, replaced in ice-cold HBSS (15-20 min), and transferred to $30 \mathrm{~mm}$ Millicel-CM $0.4 \mu \mathrm{m}$ tissue culture plate inserts (Millipore, Bedford, MA). These were placed in 6-well tissue culture plates (Corning Costar, Oneonta, NY) containing $1 \mathrm{ml}$ of culture medium (CM) consisting of: $50 \%$ MEM, 25\% horse serum, 25\% Earl's balanced salt solution supplemented with D-glucose and HEPES similar to the HBSS. HBSS and CM contained penicillin $\mathrm{G}$ and streptomycin sulfate $(5.0 \mathrm{units} / \mathrm{ml}$ and $5 \mu \mathrm{g} / \mathrm{ml}$, respectively). The slices were maintained at $36.5^{\circ} \mathrm{C}, 100 \%$ humidity, and $95 \%$ air $/ 5 \% \mathrm{CO}_{2}$ atmosphere and fed twice weekly. All solutions, antibiotics, and media were obtained from Life Technologies (Grand Island, NY).

Drugs and solutions. Culture and dissection media were as above. Balanced salt solution (BSS) contained (in $\mathrm{mM}$ ): $125 \mathrm{NaCl}, 5 \mathrm{KCl}, 1.2$ $\mathrm{NaH}_{2} \mathrm{PO}_{4}, 26 \mathrm{NaHCO}_{3}, 1.8 \mathrm{CaCl}_{2}, 0.9 \mathrm{MgCl}_{2}, 10$ D-glucose and 10 HEPES/HEPES sodium. Glucose-free BSS (gf-BSS) was prepared by omitting glucose and adding $2 \mathrm{~mm}$ 2-deoxy-D-glucose. 1,2 bis $(2-$ aminophenoxy)ethane- $N, N, N^{\prime}, N^{\prime}$-tetra-acetic acid acetoxymethyl ester (BAPTA-AM) was obtained from Teflabs (Austin, TX). EGTA-AM, 2-aminophenol- $N, N, O$-triacetic acid acetoxymethyl ester (APTRA-AM), dinitro-BAPTA-AM, and calcium green-1-acetoxymethyl ester (AM) were from Molecular Probes (Eugene, OR). The permeant chelators were prepared within $72 \mathrm{hr}$ of use as $20 \mathrm{~mm}$ stocks in anhydrous dimethyl sulfoxide (DMSO; J.T. Baker, Phillipsburg, NJ) and stored at $-20^{\circ} \mathrm{C}$.
They were diluted to their final concentrations $(10$ and $100 \mu \mathrm{M})$ in BSS and sonicated for 3 min before use. NMDA (Sigma, St. Louis, MO) was prepared as a $20 \mathrm{~mm}$ stock in distilled water and dissolved to either 10, 40, or $100 \mu \mathrm{M}$ final concentration in BSS preequilibrated to $36.5^{\circ} \mathrm{C}$ in $5 \%$ $\mathrm{CO}_{2}$. The NMDA antagonists DL-2-amino-5-phosphonovaleric acid (APV) $(300 \mu \mathrm{M}$, Sigma) and dizocilpine (MK-801, $30 \mu \mathrm{M})$ (Research Biochemicals, Natick, MA) were likewise prepared from stock solutions in gf-BSS.

Loading of slice cultures with calcium chelators. Cultures were rinsed $1 \times$ in BSS; incubated for $60 \mathrm{~min}$ at $36.5^{\circ} \mathrm{C}, 100 \%$ humidity, and a $5 \% \mathrm{CO}_{2}$ in BSS containing the given permeant $\mathrm{Ca}^{2+}$ chelator; rinsed $2 \times$ in $\mathrm{BSS}$; and maintained for an additional 30-40 $\mathrm{min}$ in the incubator before experiments. Control cultures were treated similarly with BSS containing $0.5 \%$ DMSO (the maximum quantity used in the chelator-treated slices).

The time course of BAPTA-AM loading into the slices was evaluated by loading them with $100 \mu \mathrm{M}$ custom-synthesized ${ }^{14} \mathrm{C}$-BAPTA-AM (specific activity $1.92 \mathrm{mCi} / \mathrm{mol}$, Teflabs, Austin, TX) and fixing the BAPTA molecules in situ at different time intervals after loading. The radioactive carbons in ${ }^{14} \mathrm{C}$-BAPTA-AM are located on the carboxyl residues comprising the $\mathrm{Ca}^{2+}$ chelating site, and are thus retained with the parent molecule after hydrolysis of the AM moieties. The relative ${ }^{14} \mathrm{C}$-BAPTA content in the slices was evaluated autoradiographically by exposing the slices to Hyperfilm $\beta$ max film (Amersham, UK) for $24 \mathrm{hr}$. The relative intra/extracellular distribution of ${ }^{14} \mathrm{C}$-BAPTA was evaluated by microautoradiography performed on semithin $(10 \mu \mathrm{m})$ sections of fixed cultures using high-resolution LM-1 emulsion (Amersham, UK). Fixation of BAPTA was achieved by incubating the cultures for $90 \mathrm{~min}$ with 1-ethyl3-(3-dimethylaminopropyl) carbodiimide- $\mathrm{HCl}$ (EDC, $20 \mathrm{mg} / \mathrm{ml}$; Pierce, Rockford, IL) in PBS, pH 7.4, and by overnight incubation in $4 \%(\mathrm{w} / \mathrm{v})$ paraformaldehyde in PBS (PFA). EDC cross-links carboxyl groups to primary amines found on surrounding proteins (Kendall et al., 1971; Yamamoto and Yasuda, 1977). Thus, it rapidly fixes BAPTA-free acid and other BAPTA-type chelators and permits the retention of BAPTA and its analogs in tissues during histological processing (Tymianski et al., 1997).

In some experiments, the slices were incubated as above with the fluorescent $\mathrm{Ca}^{2+}$ chelator calcium green-1/AM $(25 \mu \mathrm{M})$, fixed with EDC, and viewed with a laser-scanning confocal microscope (488 $\mathrm{nm}$ excitation, $\geq 515 \mathrm{~nm}$ emission; Bio-Rad MRC 1000, Hertfordshire, England).

Induction of anoxia. The slice cultures were rinsed twice in BSS, returned to the incubator for $30 \mathrm{~min}$, rinsed with gf-BSS for $15-20 \mathrm{~min}$, transferred to an airtight microincubator chamber (Billups-Rothenberg, Del Mar, CA), and flushed with anoxic gas $\left(5 \% \mathrm{CO}_{2}\right.$, balance $\mathrm{N}_{2}$, certified to 7 parts/million $\mathrm{O}_{2}$ in gas phase) for $60 \mathrm{sec}$ at a pressure of $5 \mathrm{psi}$. This produced a rapid fall in oxygen content (to below $0.3 \%$ ) at the level of the cultures (Fig. 1A, inset). All solutions were prewarmed and maintained at $36.5^{\circ} \mathrm{C}$. Anoxia was terminated by returning the cultures to aerated culture medium containing $2.0 \mu \mathrm{g} / \mathrm{ml}$ propidium iodide (PI; Molecular Probes), a fluorescent viability indicator.

Anoxic vulnerability of slice cultures. Anoxic vulnerability depended on two factors: the culture age [days in vitro (DIV)] and the extent of glucose deprivation. Thus, cultures were maximally vulnerable to anoxia at 12 DIV or later, and required combining $60 \mathrm{~min}$ of anoxia with aglycemia and with $2 \mathrm{~mm}$ 2-deoxy-D-glucose (2DG), an inhibitor of glucose metabolism (Fig. 1A). Anoxia without glucose deprivation was not toxic. Anoxia with glucose deprivation without $2 \mathrm{DG}$ produced little toxicity in young cultures (7-9 DIV) and incomplete injury in 12 DIV cultures (Fig. 1A). Thus, subsequent experiments were performed on 12-14 DIV cultured slices. Sixty minutes of glucose deprivation alone or in combination with 2DG was well tolerated by the cultures in the absence of anoxia, as gauged $24 \mathrm{hr}$ after the insult both by the lack of any increase in PI fluorescence (Fig. 2A) and normal neuronal morphology (Fig. 2C,E). Adding 60 min of anoxia caused intense PI fluorescence restricted to the neuronal cell layers (Fig. $2 B$; layers CA1-CA3 and DG), complete degeneration of the neuronal layers upon histological examination (Fig. $2 D)$, and marked destruction of neuronal outlines at high magnification (Fig. $2 F$ ). Therefore, all anoxia experiments were performed in the absence of glucose and in the presence of $2 \mathrm{~mm} 2 \mathrm{DG}$ (henceforth referred to as OGD).

Measurement of neuronal cell death. Sequential PI fluorescence measurements were performed in each slice culture to define both the time course and extent of cell death over $24 \mathrm{hr}$. Nuclear staining with PI indicates cell death, because it is linearly related to the degree of cell loss (Fig. $1 B$ ) gauged by counts of pyknotic nuclei in high-power photomicrographs resembling those shown in Figure $2 F$ (Newell et al., 1995). The 

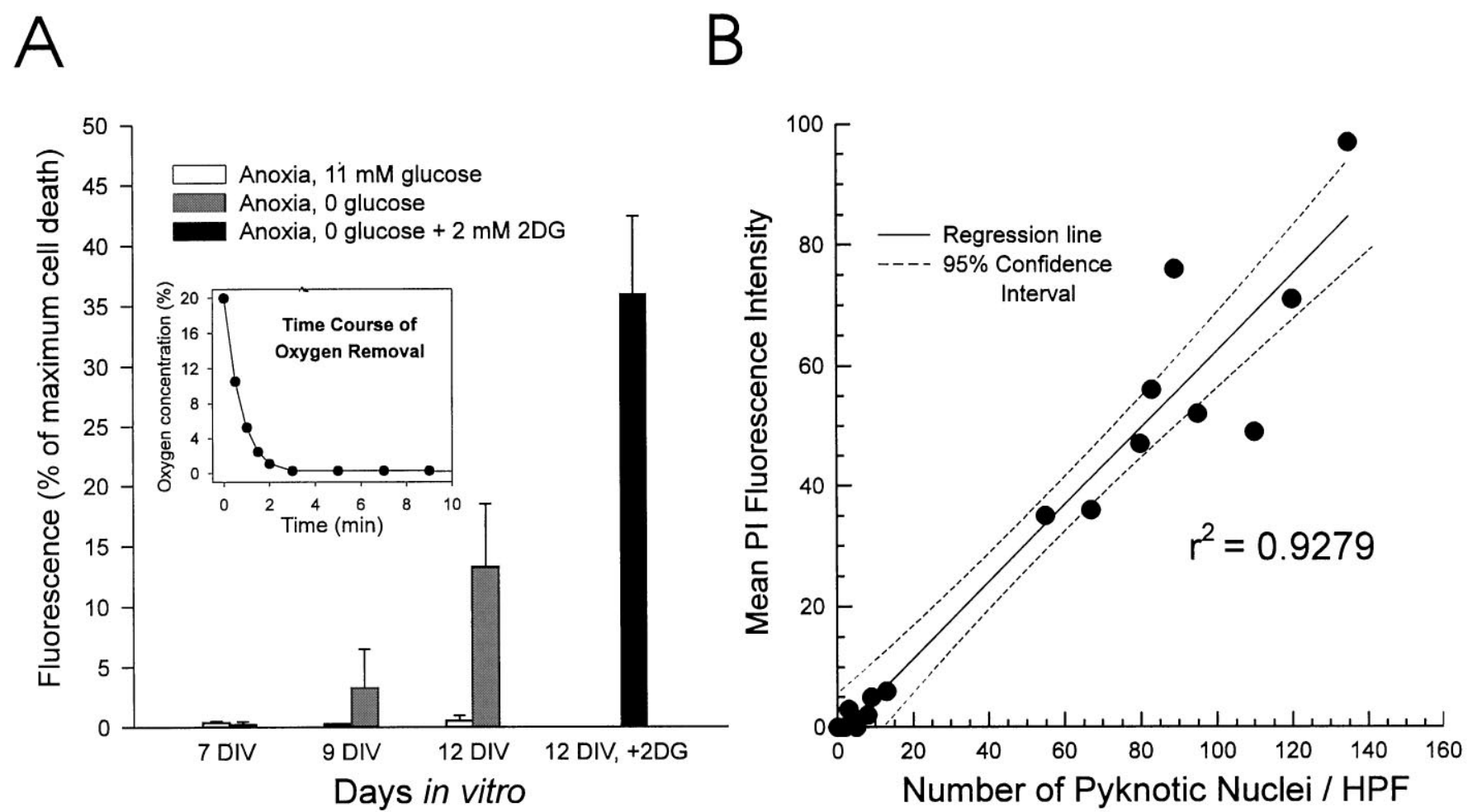

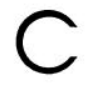
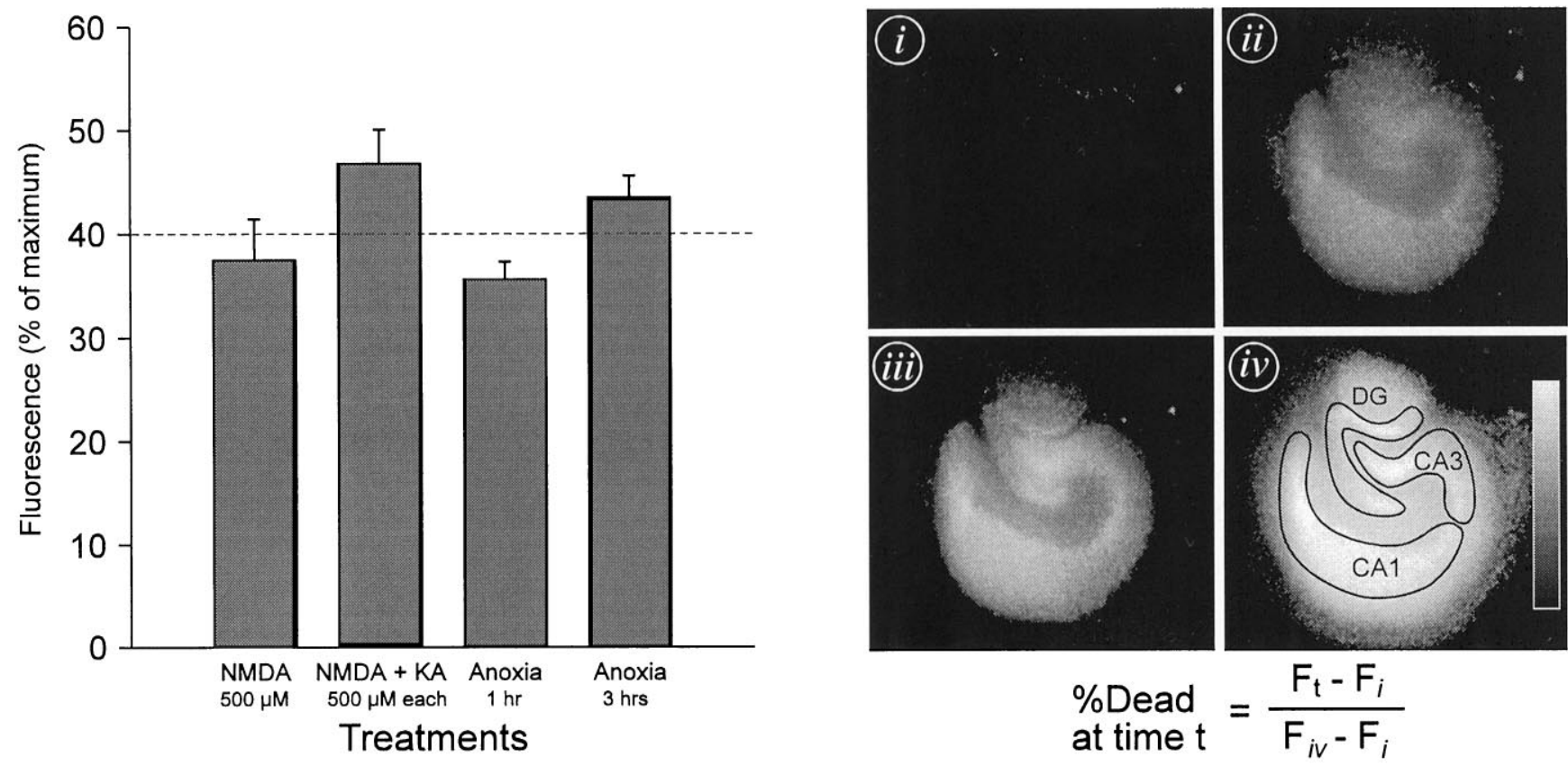

Figure 1. Characterization of organotypic hippocampal slice culture model. $A$, Anoxic vulnerability is maximal in 12 DIV or older cultures exposed to OGD, achieved by combining anoxia with aglycemia and 2DG. Cultures were exposed to $60 \mathrm{~min}$ of anoxia in the presence or absence of either D-glucose $(11 \mathrm{~mm})$ or $2 \mathrm{DG}(2 \mathrm{mM} ; n=3$ slices/group for $7-9$ DIV, 5 slices/group for $12 \mathrm{DIV}, 9$ slices/group for 12 DIV $+2 \mathrm{DG})$. Note that 60 min OGD in 12 DIV cultures caused PI fluorescence to rise to $35-40 \%$ of the maximum achieved by complete cell killing (neuronal and non-neuronal, see Materials and Methods). Sixty minutes OGD produced consistent near-total neuronal loss in the hippocampal cell layers by histological criteria (see Fig. 2). Inset, Time course of the decline in oxygen concentration after the onset of anoxia as measured with a Clarke oxygen electrode immersed in a culture well containing BSS. The electrode was calibrated at room air (20\% oxygen) and in an anoxic atmosphere obtained by a 25 min flush with $95 \%$ nitrogen $/ 5 \% \mathrm{CO}_{2}$ with analyzed oxygen content of 7 parts/million in the gas phase (nominally zero oxygen). $\mathrm{O}_{2}$ concentration at 3 min dropped to below $0.3 \% . B$, PI fluorescence intensity is linearly related to the magnitude of neuronal loss $(r=0.95, p<0.0001)$. Cultured 12 DIV hippocampal slices $(n=3)$ were exposed to OGD and fixed with $4 \%$ paraformaldehyde at 0,5 , and $24 \mathrm{hr}$ after the insult. The number of pyknotic nuclei was counted in 16 (Figure legend continues) 
advantage of measuring PI fluorescence over other toxicity assays, such as lactate dehydrogenase efflux, is that the former provides a quantitative index of cell death that can be easily repeated on the same preparation at different time intervals (Sattler et al., 1997).

To determine the cellular origin of the PI fluorescence increase produced by OGD, we first examined the distribution of cells from which the signal arose. OGD $(60 \mathrm{~min})$ produced the fluorescence pattern observed in Figure $2 B$, in which PI staining was restricted to the neuronal layers. Extending OGD from 1 to $3 \mathrm{hr}$ produced only a slightly larger increase in PI fluorescence (Fig. 1C), indicating that a near-maximal injury was already achieved by the $60 \mathrm{~min}$ insult. The damage was neuronal as determined histologically (Fig. 2) and by the fact that non-neuronal cells were unlikely to be damaged because they are considerably more resistant to anoxia (Vibulsreth et al., 1987; Rosenberg, 1991; David et al., 1996). Finally, cultures were exposed to $24 \mathrm{hr}$ applications of large concentrations of NMDA with or without kainic acid. These insults, which affect neurons almost selectively (Koh and Choi, 1987; Bruno et al., 1994; David et al., 1996), produced PI fluorescence increases of a magnitude similar to that observed with anoxic insults (Fig. 1C). Thus, a 60 min OGD produces near-complete and selective degeneration of neurons in the organotypic culture layers, which accounts for $\sim 40 \%$ of the maximal PI fluorescence achieved by complete cytodestruction (see below). This $40 \%$ of maximal PI fluorescence was therefore considered to represent $100 \%$ neuronal death in subsequent experiments.

Experimental protocols. All of the experiments were performed at $36.5^{\circ} \mathrm{C}$ in $12-14$ DIV cultures (see above). Seventy-two hours before OGD, $2.0 \mu \mathrm{g} / \mathrm{ml}$ PI was included in the culture medium. This had no harmful effects on cell survival in the slices. Baseline PI fluorescence measurements were obtained from each slice immediately before OGD (Figs. 1Di,4), and additional measurements were obtained at 1,3,5, and $24 \mathrm{hr}$ after OGD.

NMDA receptor antagonists, when used, were present in all of the solutions, from $15 \mathrm{~min}$ before OGD until the end of the experiment (usually $24 \mathrm{hr}$ ). Identical concentrations of antagonists were also added to control (uninjured) cultures. In some experiments, a 60 min NMDA application was used instead of OGD.

At the end of each experiment, the slices were lethally challenged with NMDA and kainic acid (500 $\mu \mathrm{M}$ each in BSS) for $2 \mathrm{hr}$ and incubated at $4^{\circ} \mathrm{C}$ for $24 \mathrm{hr}$. An additional PI fluorescence image of each slice was then taken and used to normalize the previous fluorescence measurements from the same slice. The intensity of PI fluorescence achieved with complete cell killing exceeded that of $60 \mathrm{~min}$ OGD by approximately 2.5-fold (Fig. 4, bottom).

Image acquisition. PI fluorescence in the cultures was viewed using an inverted microscope (Nikon Diaphot-TMD) equipped with epifluorescence optics, a low-power objective (Nikon PlanApo 4/0.20), and a rhodamine filter block (Nikon G-2A). Images were digitized at 8 bits/pixel using a video image obtained with a SIT video camera (C2400 model 8, Hamamatsu Photonics, Japan) controlled by software (Image-1, Universal Imaging, West Chester, PA) running on an 80386 microprocessorbased personal computer. Hardware gain and black level settings were optimized so that a single PI-labeled fluorescent nucleus could be clearly detected, and so maximal cell death did not saturate the camera.

Data analysis. A PI fluorescence intensity measurement for any given slice culture consisted of the sum of the fluorescence intensity values of each pixel in the image. This value was proportional to the number of injured cells in the present preparation (Newell et al., 1995) (Fig. 1B). Each PI fluorescence measurement was background-subtracted using the fluorescence image gathered immediately before OGD and normalized to

\begin{tabular}{|c|c|c|c|c|}
\hline & $\begin{array}{l}5 \mathrm{hr} \\
(\%)\end{array}$ & $\begin{array}{l}\text { ANOVA } \\
\text { result }\end{array}$ & $\begin{array}{l}24 \mathrm{hr} \\
(\%)\end{array}$ & $\begin{array}{l}\text { ANOVA } \\
\text { result }\end{array}$ \\
\hline \multicolumn{5}{|l|}{ OGD } \\
\hline CA1 & $44 \pm 3.8$ & & $98 \pm 5.1$ & \\
\hline CA3 & $45 \pm 3.9$ & $p=0.91$ & $110 \pm 7.5$ & $p=0.67$ \\
\hline DG & $43 \pm 3.5$ & & $82 \pm 9.7$ & \\
\hline \multicolumn{5}{|c|}{ OGD + BAPTA-AM } \\
\hline CA1 & $20 \pm 2.5$ & & $85 \pm 6.1$ & \\
\hline CA3 & $14 \pm 3.8$ & $p=0.41$ & $85 \pm 7.6$ & $p=0.95$ \\
\hline DG & $15 \pm 4.2$ & & $82 \pm 6.2$ & \\
\hline \multicolumn{5}{|l|}{ NMDA } \\
\hline CA1 & $58 \pm 3.9$ & & $104 \pm 4.3$ & \\
\hline CA3 & $47 \pm 5.6$ & $p=0.09$ & $96 \pm 9.3$ & \\
\hline DG & $41 \pm 4.2$ & & $74 \pm 4.9^{*}$ & $p \pm 0.02$ \\
\hline \multicolumn{5}{|c|}{ NMDA + } \\
\hline \multicolumn{5}{|c|}{ BAPTA-AM } \\
\hline CA1 & $57 \pm 4.9$ & & $111 \pm 8.9$ & \\
\hline CA3 & $50 \pm 7.6$ & $p=0.44$ & $102 \pm 17.9$ & $p=0.30$ \\
\hline DG & $45 \pm 6.6$ & & $79 \pm 15.8$ & \\
\hline
\end{tabular}

Neurons in the different regions of the hippocampal culture behave similarly when exposed to OGD, NMDA, and BAPTA-AM. Slice cultures were exposed either to 60 min OGD, $60 \mathrm{~min}$ OGD in the presence of BAPTA-AM $(100 \mu \mathrm{M}), 60 \mathrm{~min}$ of NMDA $(100 \mu \mathrm{M})$, or $60 \mathrm{~min}$ of NMDA in the presence of BAPTA-AM. The mean $\pm \mathrm{SE}$ percentage of neuronal death in each hippocampal region is shown at 5 and $24 \mathrm{hr}$ after the insult ( $n=9$ slice cultures/group). Differences between means within groups were sought by ANOVA. All exposures and treatments had similar effects on neuronal death in each hippocampal region, thus supporting the rationale for pooling the fluorescence values from the entire slice for analysis. DG, Dentate gyrus. *, Significantly different from CA1 in same group (ANOVA with post hoc $t$ test with Bonferroni correction).

the maximal fluorescence obtained from the same slice after complete cell killing. Thus, the percentage of cell death in each experiment was expressed as:

$$
\% \text { Death }=\frac{100 \times\left(F_{t}-F_{\mathrm{b}}\right)}{\left.F_{\max }-F_{\mathrm{b}}\right)}
$$

where $F_{t}$ is slice fluorescence at time $t, F_{\mathrm{b}}$ is background fluorescence at the start of the experiment, and $F_{\max }$ is maximal fluorescence after complete cell killing (Fig. 1Div). In some experiments, the same approach was used to examine the effects of injury and treatment on cell death in specific hippocampal regions (CA1, CA3, and dentate gyrus) by obtaining the PI fluorescence values from these regions of interest separately, as shown in Figure 1Div. This separate analysis revealed that, unlike in the hippocampus in vivo, neurons in these regions in slice cultures behaved similarly with respect to their survival responses to NMDA, OGD, and to treatment with $\mathrm{Ca}^{2+}$ chelators (Table 1). All data were examined using ANOVA with the Newman-Keuls procedure to evaluate differences between individual group means. All means are shown with their SE.

$\leftarrow$

high-power fields in the neuronal layers, and the counts were plotted against the PI fluorescence intensity obtained from the same fields immediately before fixation. $C$, PI fluorescence produced by $60 \mathrm{~min}$ OGD is of neuronal origin. Cultures were exposed to $500 \mu \mathrm{M}$ NMDA ( $n=8$ slices) or to $500 \mu \mathrm{M}$ each of NMDA and kainate ( $n=8$ slices) for $24 \mathrm{hr}$, or to either 1 or $3 \mathrm{hr}$ of OGD $(n=7$ and 9 slices, respectively) followed by a $24 \mathrm{hr}$ incubation in BSS. PI fluorescence was normalized to that obtained from the same slices after complete cell killing. Both the NMDA and the 1 hr OGD insults produced only neuronal cell loss as gauged histologically (as in Fig. 3). The combined NMDA and kainate insult, as well as the $3 \mathrm{hr}$ OGD insult, killed an additional cell population ( $p<0.05$, one-tailed Student's $t$ test) that was resistant to $500 \mu \mathrm{M}$ NMDA or 60 min of OGD, and was most likely glial, although a contribution from a small resistant neuronal population outside the neuronal layers cannot be excluded. PI fluorescence values obtained by OGD and the EAA insults were $\sim 40 \%$ of the maximum. Thus, the value of $40 \%$ of maximal fluorescence (horizontal dotted line) was selected in subsequent analyses as equating $100 \%$ neuronal death. $D$, Method of calculating cell death at a given time $t$ from PI fluorescence images. Images of the cultures were taken before (i) and during (ii and iii) the $24 \mathrm{hr}$ observation period and normalized to the maximal PI fluorescence values obtained with complete cell killing (iv). The formula shown was applied to the pooled fluorescence from the entire image or to fluorescence values derived from regions of interest (ROIs; solid lines in $i v$ ) encompassing the $C A 1, C A 3$, or dentate granule layer $(D G)$ of the culture. ROIs were selected on the final PI image (iv) and then applied to the previous images in the same series $(i-i i i)$. Gray-level scale in iv applies to all images. 

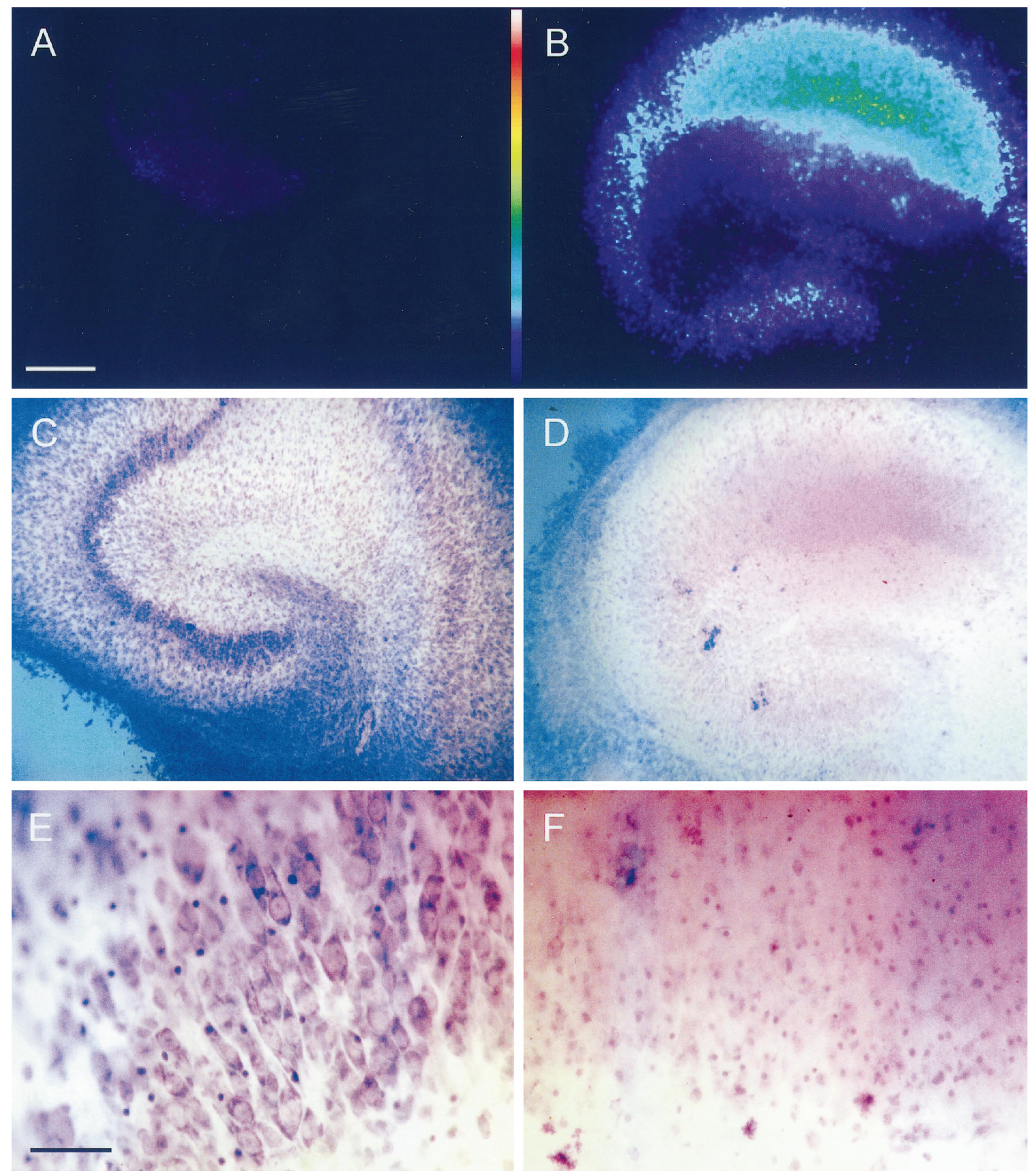

Figure 2. OGD causes complete neurodegeneration of all neuronal layers in organotypic hippocampal slices, whereas glucose deprivation alone does not. Cultures were maintained in BSS containing $2 \mu \mathrm{g} / \mathrm{ml}$ PI and exposed to anoxia/aglycemia $+2 \mathrm{~mm} 2 \mathrm{DG}(B, D, F)$ or to aglycemia $+2 \mathrm{~mm} 2 \mathrm{DG}$ without anoxia $(A, C, E)$. After $24 \mathrm{hr}$, PI fluorescence was digitally imaged in the slices $(A, B)$, after which they were fixed in $4 \%$ paraformaldehyde and stained with toluidine blue/acid fuchsin $(C-F)$. No significant PI staining was observed in slices challenged with glucose deprivation alone $(A)$, whereas OGD produced a significant increase in PI fluorescence in all neuronal layers $(B)$. Similarly, glucose-deprived cultures exhibited normal neuronal morphology, whereas OGD-challenged slices sustained widespread neuronal loss at both low $(4 \times$ objective; $C, D)$ and high $(40 \times$ objective; $E, F)$ magnification. Thus, anoxic damage is reflected by intense PI staining $(B)$, loss of neuronal cell layers at low magnification $(D)$, and the replacement of neuronal outlines with pyknotic nuclei at higher magnification $(F) . A$ and $B$ are digital, 8-bit/pixel pseudocolor images of PI fluorescence intensity, with purple and red representing low and high intensities, respectively (color bar). $C-F$ are true-color images of the slices in $A$ and $B$ after staining with toluidine blue/acid fuchsin. The pale blue background in $C$ and $D$ is produced by toluidine blue staining of the membrane, on which the slices are cultured. Scale bars: 500 $\mu \mathrm{m}$ in $A-D$ (shown in $A$ ); $75 \mu \mathrm{m}$ in $E$ and $F$ (shown in $E$ ). 


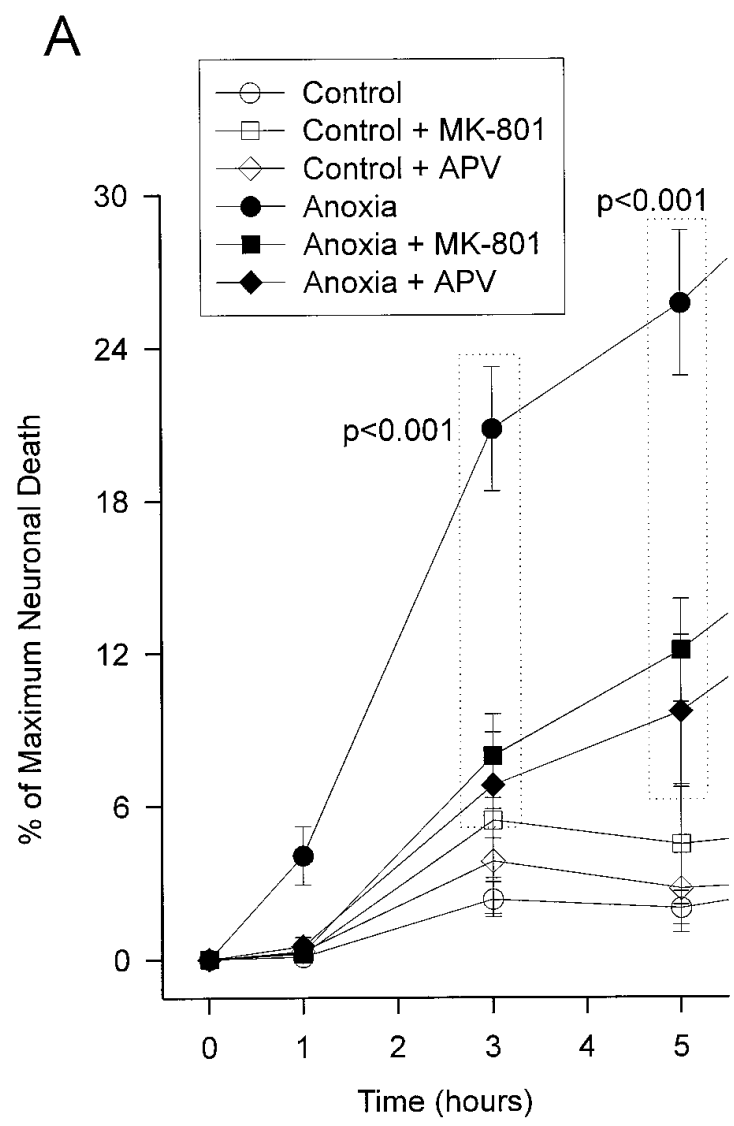

B

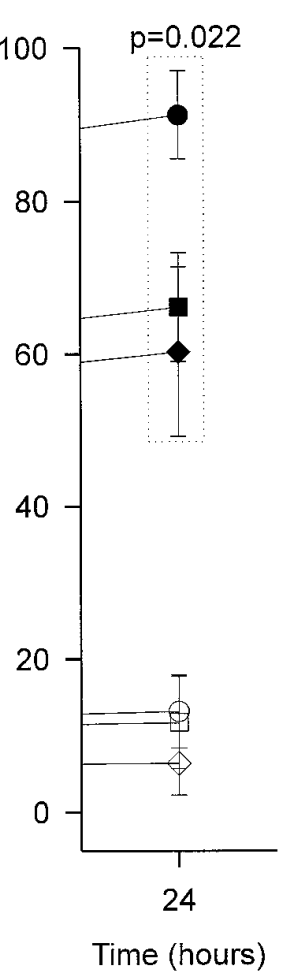

C
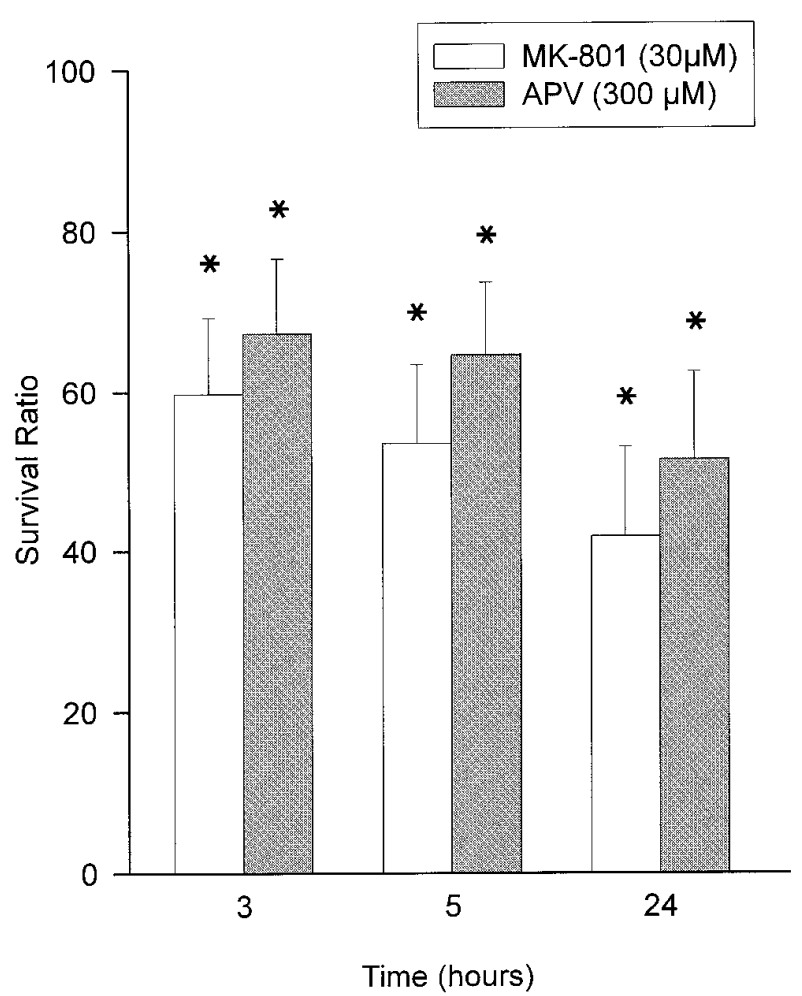

Figure 3. OGD-induced neuronal injury is partially mediated by NMDA receptor activation. Slice cultures were exposed to 60 min OGD alone (11 slices) or in the presence of $30 \mu \mathrm{M}$ MK-801 (11 slices) or $300 \mu \mathrm{M}$ DL-APV (9 slices). Antagonists were present from 15 min before OGD until the end of the $24 \mathrm{hr}$ period. $A, B$, Representative series of experiments. Both antagonists equally reduced anoxic injury when compared with untreated anoxic slices (ANOVA followed by the Newman-Keuls procedure for multiple comparisons; groups included are in dotted boxes, $p$ values marked on plot). Open symbols, Glucose deprivation in the presence of $2 \mathrm{~mm} 2 \mathrm{DG}$ without anoxia (no treatment, 11 slices; MK-801, 11 slices; APV, 13 slices). $A$, Time course of neuronal cell death at $0-5 \mathrm{hr} . B$, Extent of neuronal death at $24 \mathrm{hr}$ (note differences in ordinate between $A$ and $B$ ). $C$, Effect of NMDA antagonists on the survival of OGD-challenged neurons over $24 \mathrm{hr}$. Data were pooled from two series of experiments using MK-801 (22 total slices) and APV (23 slices). Protective efficacy of a treatment was expressed as a survival ratio, defined as $100 \times\left(1-D_{\text {treated }} / D_{\text {untreated }}\right)$, where $D_{\text {treated }} / D_{\text {untreated }}$ is the ratio of OGD-induced neuronal death in the antagonist treated and untreated groups, respectively. A value of 100 indicates that the treatment completely prevented neuronal death, whereas 0 indicates no effect of treatment. Asterisks indicate significant differences from zero.

\section{RESULTS}

We examined whether increasing the $\mathrm{Ca}^{2+}$ buffering capacity of neurons reduces the neurotoxic sequelae of OGD, whether such manipulation has neurotoxic potential, and whether the mechanism underlying these effects is pre- or postsynaptic. Experiments were performed in 12-14 DIV organotypic hippocampal cultures exposed to 60 min OGD (Fig. $1 A$ ). Neuronal survival was measured quantitatively with the fluorescent viability marker PI at various time intervals for $24 \mathrm{hr}$ after the insult (Fig. $1 \mathrm{~B}$ ). The 60 min OGD insult selectively injured neurons in the hippocampal cell layers (Figs. $1 C, 2 A-F$; see Materials and Methods). Neurons in the different regions of the hippocampus (CA1, CA3, and dentate gyrus; Fig. 1Div) behaved similarly with respect to their vulnerability to OGD and NMDA application; they also responded similarly to treatment (Table 1).

\section{OGD neurotoxicity is mediated partially by NMDA receptor activation}

Previous studies suggest that exogenous $\mathrm{Ca}^{2+}$ chelators may affect NMDA receptor-mediated glutamatergic mechanisms. The chelators may act postsynaptically by attenuating neuro- toxic NMDA-mediated cytosolic calcium loading (Tymianski et al., 1994a) and/or presynaptically by attenuating excitatory neurotransmitter release (Tymianski et al., 1994b; Ouanounou et al., 1996; Spigelman et al., 1996). Thus, we first examined the role of NMDA receptor activation in OGD toxicity in the present preparation. Also, because a 60 min OGD insult produces near complete death of all neurons in the slice (see Materials and Methods; Figs. $1 C, 2$ ), it was necessary to establish whether this severe insult is at all amenable to therapeutic manipulation.

Before the 60 min OGD insult, the cultures were pretreated with either DL-APV $(300 \mu \mathrm{M})$ or MK-801 $(30 \mu \mathrm{M})$, a competitive and a noncompetitive NMDA antagonist, respectively. The antagonists were also included in the extracellular solution for the subsequent $24 \mathrm{hr}$ observation period. Both NMDA receptor antagonists were equally effective in attenuating OGD neurotoxicity. The effects of both antagonists on the time course and extent of neurotoxicity were manifest within the first hour after insult (Fig. $3 A$ ) and persisted for $24 \mathrm{hr}$ (Fig. 3B,C). Treated slices exhibited between 40 and $50 \%$ improved neuronal survival over similarly 


\section{Anoxia}
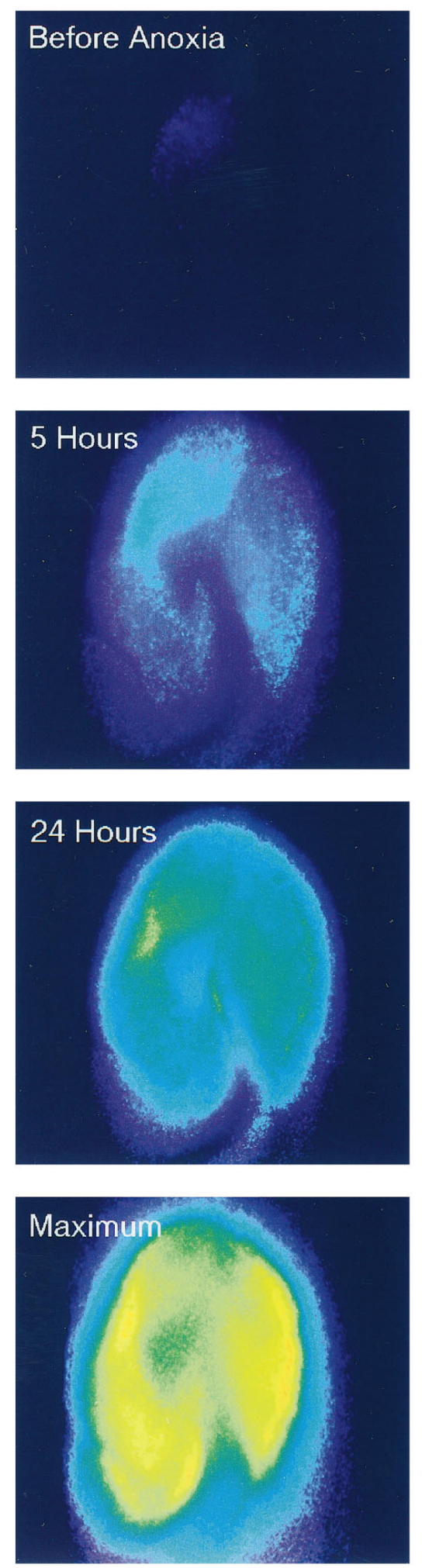

\section{Anoxia + MK801}
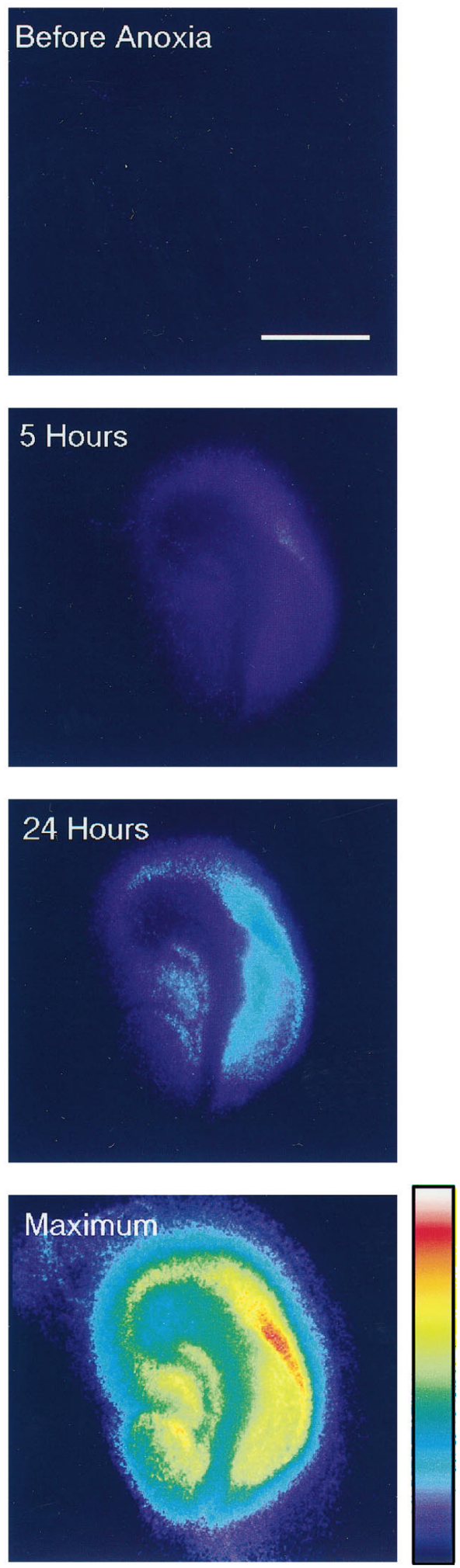

Figure 4. MK-801, an NMDA receptor antagonist, attenuates neuronal damage produced by OGD: representative experiment. Pseudocolor images of PI fluorescence in cultures exposed to OGD (left column) and to OGD combined with MK-801 (30 $\mu \mathrm{M}$; right column) at the indicated times. The panels at the bottom illustrate the maximum achievable PI fluorescence (after a further $24 \mathrm{hr}$ incubation at $4^{\circ} \mathrm{C}$ ) used to normalize the previous measurements from the same slice. MK- 801 pretreatment (15 min before the insult) improved neuronal survival (see Fig. 3). Color scale indicates the relationship between color and fluorescence intensity, with purple and red representing low and high intensities, respectively. Scale bar, $1 \mathrm{~mm}$.

time point examined compared with the untreated injured control. Thus, OGD toxicity, presumably triggered by synaptic overactivity and endogenous glutamate release, is mediated to a significant degree by NMDA receptor activation as it is attenuated

by NMDA antagonists. challenged, untreated controls (Fig. $3 C$ ). The representative PI fluorescence images in Figure 4 illustrate both the time course and extent of neurotoxicity in cultures exposed to OGD (left column) or to OGD with MK-801 (right column). Adding the NMDA antagonist visibly reduced the increase in PI fluorescence at each 
Incubating cultured slices with BAPTA-AM results in intraneuronal chelator accumulation

The loading of AM derivatives of BAPTA into neurons in thick tissue sections is more problematic than in dissociated cultures. The difficulty is ascribed to the intervening extracellular matrix (which limits access to neurons) (Yuste and Katz, 1991) and is solved partially by using higher concentrations of AM analogs (Dani et al., 1992). Because intracellular delivery of $\mathrm{Ca}^{2+}$ buffers was critical to the present study, we first determined whether loading organotypic slices with permeant buffers achieves intraneuronal chelator accumulation.

Slice cultures were loaded with ${ }^{14} \mathrm{C}$-BAPTA-AM and fixed with EDC (see Materials and Methods). The method of EDC fixation distinguished between BAPTA-AM and its deesterified forms because the cross-linking reaction involves the carboxylic acids of the $\mathrm{Ca}^{2+}$ chelating site (Tymianski et al., 1997). The fixed slices were sectioned $(10 \mu \mathrm{m})$, coated with photo emulsion, and evaluated by microautoradiography (Fig. $5 A$, representative section). This revealed a preferential localization of silver grains over neuronal cell layers $(66.4 \pm 3.1$ over cell layers compared with $43.2 \pm 2.1$ outside cell layers; units are grains/surface area unit, means indicated differed by Student's $t$ test, $p<0.0001$ ).

To evaluate with greater accuracy the spatial distribution of BAPTA-like compounds in loaded slices, cultures were loaded with the fluorescent BAPTA analog calcium green-1-AM $(25 \mu \mathrm{M})$ and examined by confocal microscopy. Visualization of distinct cell layers was poor in the first hour because of the presence of calcium green-1-AM precipitates overlying the slice tissue (data not shown). To better visualize the intraneuronal chelator salt without the confounding presence of calcium green-AM, some slices were fixed with EDC, washed many times, sectioned (10 $\mu \mathrm{m})$, and imaged. This approach revealed unambiguously the presence of the indicator in the intraneuronal compartment (Fig. $5 B, C)$.

\section{BAPTA-AM pretreatment temporarily protects against OGD-induced neurodegeneration}

Slice cultures were pretreated at $36.5^{\circ} \mathrm{C}$ with different concentrations of BAPTA-AM. OGD was initiated for 60 min within 45-60 min after loading was completed. Neuronal death was then measured at different time intervals for $24 \mathrm{hr}$. The representative experiments in Figure 6, $A$ and $B$, illustrate that pretreatment with both 10 and $100 \mu \mathrm{M}$ BAPTA-AM was well tolerated by control cultures, showing no untoward effects of the drug treatment alone. Both chelator concentrations attenuated considerably the toxicity of 60 min OGD throughout the first hour of observation, with the higher BAPTA concentration having a slightly greater effect (Fig. $6 A$ ). The extent of early protection by BAPTA was similar to that of NMDA receptor antagonists (compare Fig. $3 A$ to Fig. $6 A$ and Fig. $3 C$ to Fig. $6 C$ ). However, unlike treatment with NMDA antagonists, protection by BAPTA-AM pretreatment did not persist until the $24 \mathrm{hr}$ time point (Fig. 6B).

\section{The time course of ${ }^{14} \mathrm{C}$-BAPTA retention in the cultured slices parallels exactly the time course of neuroprotection}

A disadvantage of using cell membrane-permeant forms of BAPTA to enhance $\mathrm{Ca}^{2+}$ buffering is that the intracellular concentrations of the chelator are difficult to estimate. Also, because these compounds are metabolized (Tsien, 1981; Van Der Zee et al., 1989) and extruded from cells (Di Virgilio et al., 1990; Munsch and Deitmer, 1995; Ouanounou et al., 1996), their kinetics are difficult to predict. Therefore, to determine the cause of the transient neuroprotective action of BAPTA-AM seen presently, we examined the time course of BAPTA retention in the cultures.

Slices were loaded with ${ }^{14} \mathrm{C}$-BAPTA-AM, fixed at $0,3,5,10$, and $24 \mathrm{hr}$ after loading with EDC (see Materials and Methods), and studied by autoradiography. The time course of ${ }^{14} \mathrm{C}$-BAPTA retention in the slice tissue is shown qualitatively in the representative ${ }^{14} \mathrm{C}$-BAPTA autoradiographs in Figure $7 A$, and quantitatively by densitometric analysis (Fig. $7 B$ ). Tissue ${ }^{14} \mathrm{C}$-BAPTA content remained stable for the first $5 \mathrm{hr}$ after loading, followed by a rapid decline to nearly $50 \%$ of initial levels at $10 \mathrm{hr}$, and a fall to below $15 \%$ of initial values by $24 \mathrm{hr}$. This time course paralleled exactly the time course of neuroprotection by BAPTA-AM after OGD (compare Fig. $6 C$ to Fig. $7 B$ ).

These experiments (Figs. 6,7) contrast with those using NMDA antagonists (Figs. 3, 4), in which the antagonists could be maintained at their site of action throughout the $24 \mathrm{hr}$ observation period. They illustrate that the neurotoxic processes triggered by OGD are $\mathrm{Ca}^{2+}$-dependent and remain active for many hours beyond the initial insult, because toxicity could be blocked both while NMDA antagonists were present outside the cells $(24 \mathrm{hr})$ and while $\mathrm{Ca}^{2+}$ buffering was elevated within the cells (several hours). The nature of these neurotoxic processes is presently unclear. However, brief anoxic or excitotoxic insults in other preparations (such as primary striatal cultures, cerebellar granule cells, and acute hippocampal slices) have been shown to trigger persistent secondary processes, including the delayed formation of nitric oxide, a prolonged release of endogenous EAAs for hours after terminating the initiating insult, longstanding cell membrane depolarization that exceeds the duration of the primary insult, longstanding failure of synaptic transmission, and prolonged disturbances in cell energy metabolism (Kass and Lipton, 1982, 1986; Novelli et al., 1988; Strijbos et al., 1996).

\section{The protective effect is attributable to intracellular BAPTA and not to extracellular BAPTA or the AM moiety}

The identical time courses of neuroprotection and of ${ }^{14} \mathrm{C}$-BAPTA retention are insufficient to prove causality between the presence of intracellular BAPTA and the protective effect. However, identical pretreatment of cultured slices with $100 \mu \mathrm{M}$ BAPTA tetrapotassium salt, which is cell-impermeant, had no effect on the time course and extent of neurodegeneration after OGD, indicating that extracellular $\mathrm{Ca}^{2+}$ chelation was not responsible for neuroprotection (Fig. 8). Also, pretreating slices with dinitro-BAPTAAM, a chelator having a negligible affinity for $\mathrm{Ca}^{2+}$ ions $\left(K_{\mathrm{d}} \sim 25\right.$ $\mathrm{mM}$ ), also had no significant effect on cultures exposed to OGD (Fig. 8). Thus, the observed effects of BAPTA-AM were specifically attributable to enhancement of intracellular $\mathrm{Ca}^{2+}$ buffering, rather than to effects of the AM moiety or to nonspecific pharmacological phenomena related to the BAPTA structure, since these are also provided by dinitro-BAPTA-AM.

These findings, along with the results in Figures 5-7, indicate unequivocally that enhancing neuronal $\mathrm{Ca}^{2+}$ buffering either attenuates, or delays by many hours, the onset of anoxic neurodegeneration.

\section{$\mathrm{Ca}^{2+}$ buffers are ineffective as neuroprotectants when transmitter release is bypassed}

If synaptic overactivity mediates anoxic cell death (Kass and Lipton, 1982; Rothman, 1983, 1984), then protection by $\mathrm{Ca}^{2+}$ buffers, which attenuate synaptic transmitter release in many preparations (Adler et al., 1991; Niesen et al., 1991; Tymianski et 


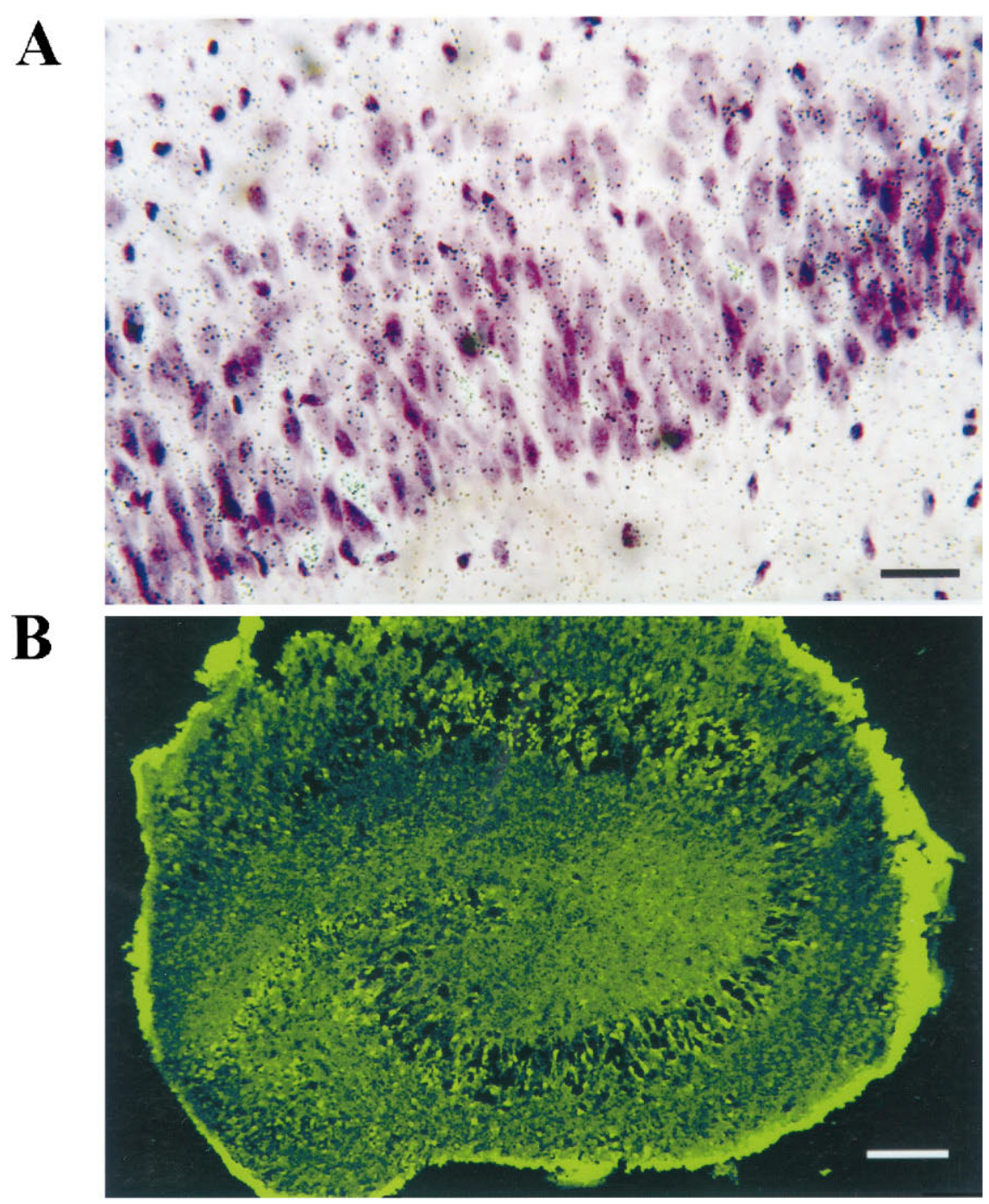

Figure 5. Treating slice cultures with BAPTA-AM and BAPTA analogs results in intraneuronal chelator accumulation. $A$, Cellular autoradiography of the CA1 region from a $10-\mu \mathrm{m}$-thick section of a ${ }^{14} \mathrm{C}$ BAPTA-AM-loaded slice culture $(40 \times$ microscope objective) counterstained with hematoxylin and eosin. The slice was loaded with $100 \mu \mathrm{M}{ }^{14} \mathrm{C}$ BAPTA-AM (see Materials and Methods) and fixed with EDC $24 \mathrm{hr}$ after loading. There was a higher density of silver grains over the cell layers (see Results). Scale bar, $40 \mu \mathrm{m}$. $B$, Confocal image of a slice culture similarly loaded with the fluorescent cellpermeant BAPTA analog calcium green-AM (25 $\mu \mathrm{M}$ ), fixed after $5 \mathrm{hr}$ with EDC (see Results), and sectioned $(10 \mu \mathrm{m})$. Distinct localization of the compound was detected in cell layers. Scale bar, $300 \mu \mathrm{m}$. $C$, Higher magnification of an area from the slice in $B$ confirms intraneuronal loading of calcium green. Scale bar, $20 \mu \mathrm{m}$. Data in $A$ and $B$ are representative of five experiments per group.

\section{C}

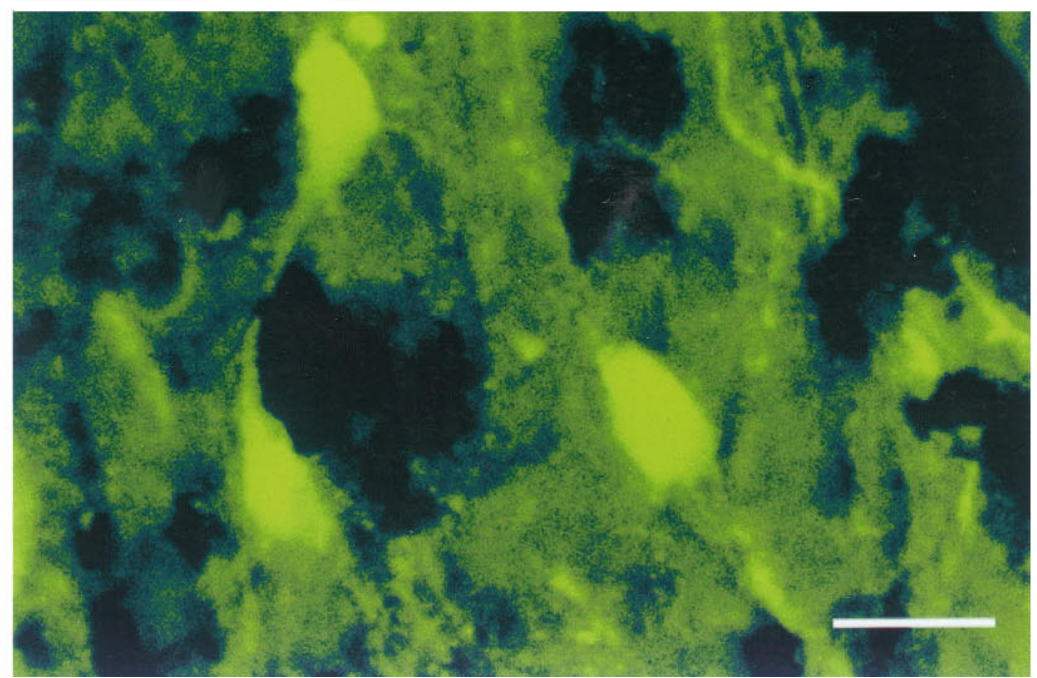

al., 1994b; Ouanounou et al., 1996; Spigelman et al., 1996), may occur by this mechanism. However, exogenous $\mathrm{Ca}^{2+}$ buffers also attenuate postsynaptic cytosolic $\mathrm{Ca}^{2+}$ increases in neurons (Tymianski et al., 1993c, 1994a). Because $\mathrm{Ca}^{2+}$ loading triggers neurotoxicity (Choi, 1988; Hartley et al., 1993; Tymianski et al., 1993a,b; Lu et al., 1996), the protective effects of BAPTA-AM could be ascribed to this postsynaptic mechanism.
To examine this presently, the process of synaptic transmitter release was bypassed by exposing the cultures to NMDA, rather than to OGD. This maneuver directly activates postsynaptic NMDA receptors and produces toxicity similar to OGD (Fig. 1C). If $\mathrm{Ca}^{2+}$ buffers protect by presynaptic mechanisms, then they should be ineffective when the insult is produce by adding exogenous excitotoxin. 
A

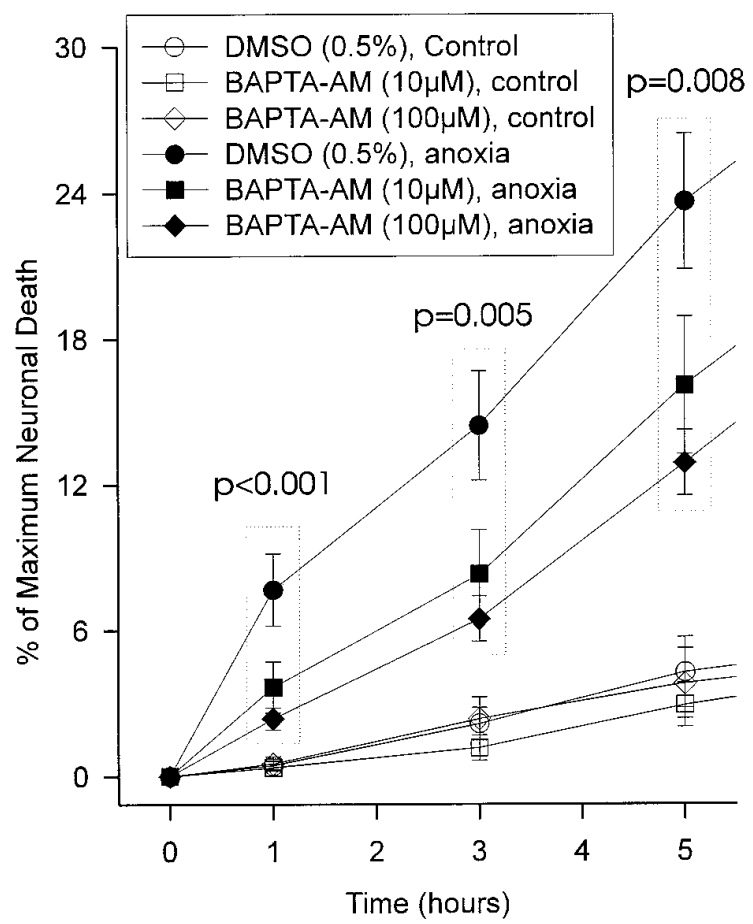

B

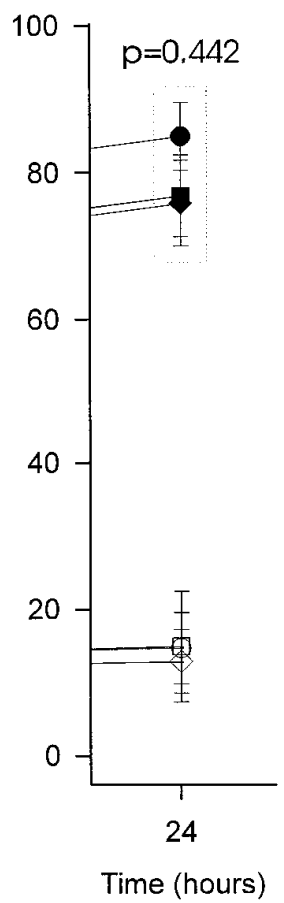

C

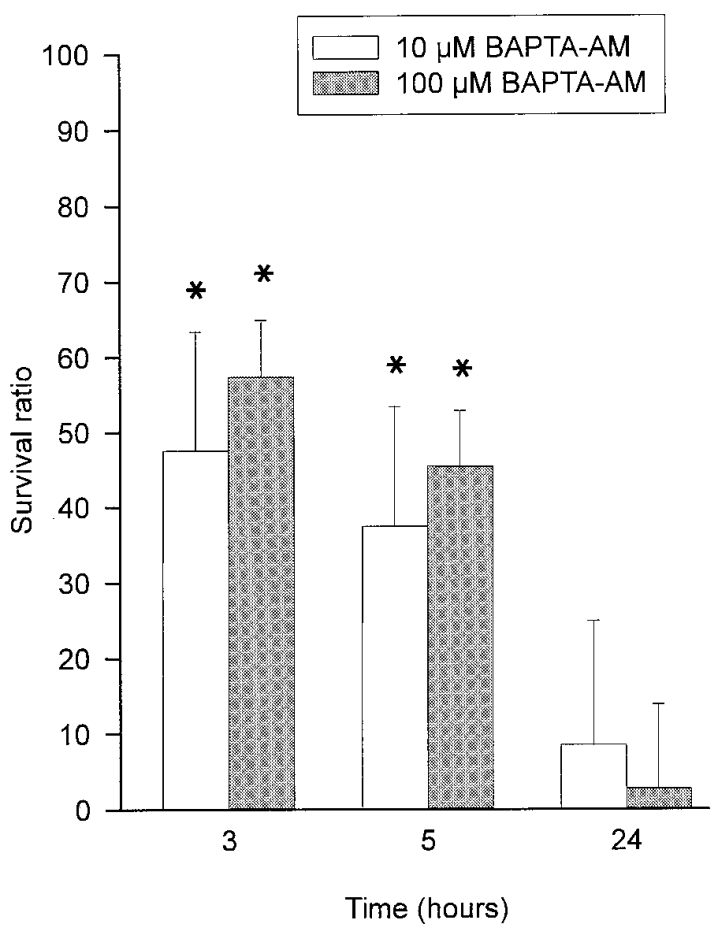

Figure 6. Pretreatment with BAPTA-AM temporarily protects cultured slices from OGD. The slices were pretreated with BAPTA-AM (10 or $100 \mu \mathrm{M}$, $n=18$ and 19 slices, respectively) in a total of $0.5 \%$ DMSO or with DMSO alone. Subsequently, they were exposed to 60 min OGD. $A, B$, Representative series of experiments. $A$, OGD-induced cell death was significantly lower in both BAPTA-treated groups at 1,3 , and $5 \mathrm{hr}$ after the insult compared with untreated OGD controls ( $n=17$ slices). $B$, At $24 \mathrm{hr}$, however, this protective effect of BAPTA pretreatment was no longer significant (ANOVA followed by Newman-Keuls procedure for multiple comparisons; groups included are in dotted boxes, $p$ values marked on plot). Open symbols, Glucose deprivation without anoxia (DMSO, $10 \mu \mathrm{M}$ and $100 \mu \mathrm{M}$ BAPTA-AM groups, $n=9$, 6 , and 8 slices, respectively). $C$, Effect of BAPTA-AM on the survival of OGD-challenged neurons over $24 \mathrm{hr}$. Data were pooled from two series of experiments using $10 \mu \mathrm{M}$ BAPTA-AM pretreatment (18 slices) and five series of experiments with $100 \mu \mathrm{M}$ BAPTA-AM (66 slices). Survival ratios were calculated as in Figure $4 C$. At 3 and 5 hr after OGD, the survival ratios of 10 and $100 \mu \mathrm{M}$ BAPTA-AM pretreatments were comparable to those resulting from NMDA antagonists. However, unlike with NMDA antagonists, a protective effect of BAPTA was no longer observed at $24 \mathrm{hr}$. Asterisks indicate significant differences from zero (no treatment effect).

The cultures were pretreated as before with $100 \mu \mathrm{M}$ of either: BAPTA-AM, EGTA-AM (a slow buffer with similar $\mathrm{Ca}^{2+}$ affinity to BAPTA) or APTRA-AM (a fast buffer with a lower $\mathrm{Ca}^{2+}$ affinity than BAPTA; see below). The cultures were then challenged for $60 \mathrm{~min}$ with a range of concentrations of NMDA (10, 40, and $100 \mu \mathrm{M})$.

Neurons in both chelator-treated and untreated cultures exposed to $10 \mu \mathrm{M}$ NMDA were unaffected by this insult, and no adverse effects of the chelators were noted (Fig. 9A). By contrast, a $100 \mu \mathrm{M}$ NMDA exposure caused almost complete, widespread neuronal death, which also remained unaffected in the presence of the chelators (Fig. 9A). Furthermore, an intermediate exposure to NMDA $(40 \mu \mathrm{M})$ actually potentiated, rather than reduced, cell death in cultures treated with BAPTA-AM (Fig. 9A-C). However, this potentiated toxicity was not seen with either EGTA-AM or with APTRA-AM (Fig. 9A-C). The inability of any of the chelators to attenuate NMDA toxicity is consistent with a presumed presynaptic site for their neuroprotective action. The increased toxicity of intermediate NMDA concentrations in the presence of BAPTA-AM is also consistent with previous reports in which BAPTA-AM pretreatment of cell cultures enhanced or accelerated the toxicity of L-glutamate or NMDA challenges (Baimbridge and Abdel-Hamid, 1992; Dubinsky, 1993; Abdel-Hamid, 1994).

\section{APTRA-AM, a permeant buffer that selectively attenuates transmitter release, is also protective}

Exogenous $\mathrm{Ca}^{2+}$ buffers attenuate transmitter release by dissipating the gradients of high presynaptic $\left[\mathrm{Ca}^{2+}\right]_{\mathrm{i}}$ required to trigger the release process (Adler et al., 1991; Roberts, 1993). Because $\left[\mathrm{Ca}^{2+}\right]_{\mathrm{i}}$ must rise to micromolar levels for release to occur (Smith and Augustine, 1988), chelators having a relatively low $\mathrm{Ca}^{2+}$ affinity may be as potent at attenuating release as high-affinity buffers. For example, APTRA, whose $K_{\mathrm{d}}$ for $\mathrm{Ca}^{2+}$ is in the 20-25 $\mu \mathrm{M}$ range, attenuates excitatory transmitter release in acute hippocampal slices as effectively as BAPTA $\left(K_{\mathrm{d}}\right.$ of $\left.100-400 \mathrm{nM}\right)$ (Spigelman et al., 1996). In contrast to their presynaptic actions, however, buffers with micromolar $\mathrm{Ca}^{2+}$ affinity have little effect on postsynaptic $\left[\mathrm{Ca}^{2+}\right]_{\mathrm{i}}$ increases evoked by EAAs (Tymianski et al., 1994a), and may thus be used to separate presynaptic from postsynaptic effects.

Figure 10, $A$ and $B$, shows that in cultured slices loaded with 100 $\mu \mathrm{M}$ APTRA-AM before 60 min OGD, neuroprotection was observed at 3 and $5 \mathrm{hr}$ but not at $24 \mathrm{hr}$, an effect similar to that of BAPTA-AM. This finding and the ineffectiveness of both BAPTA-AM and APTRA-AM in the face of a direct NMDA insult (see above) further support a presynaptic site of action for the neuroprotective mechanism of $\mathrm{Ca}^{2+}$ buffers. 

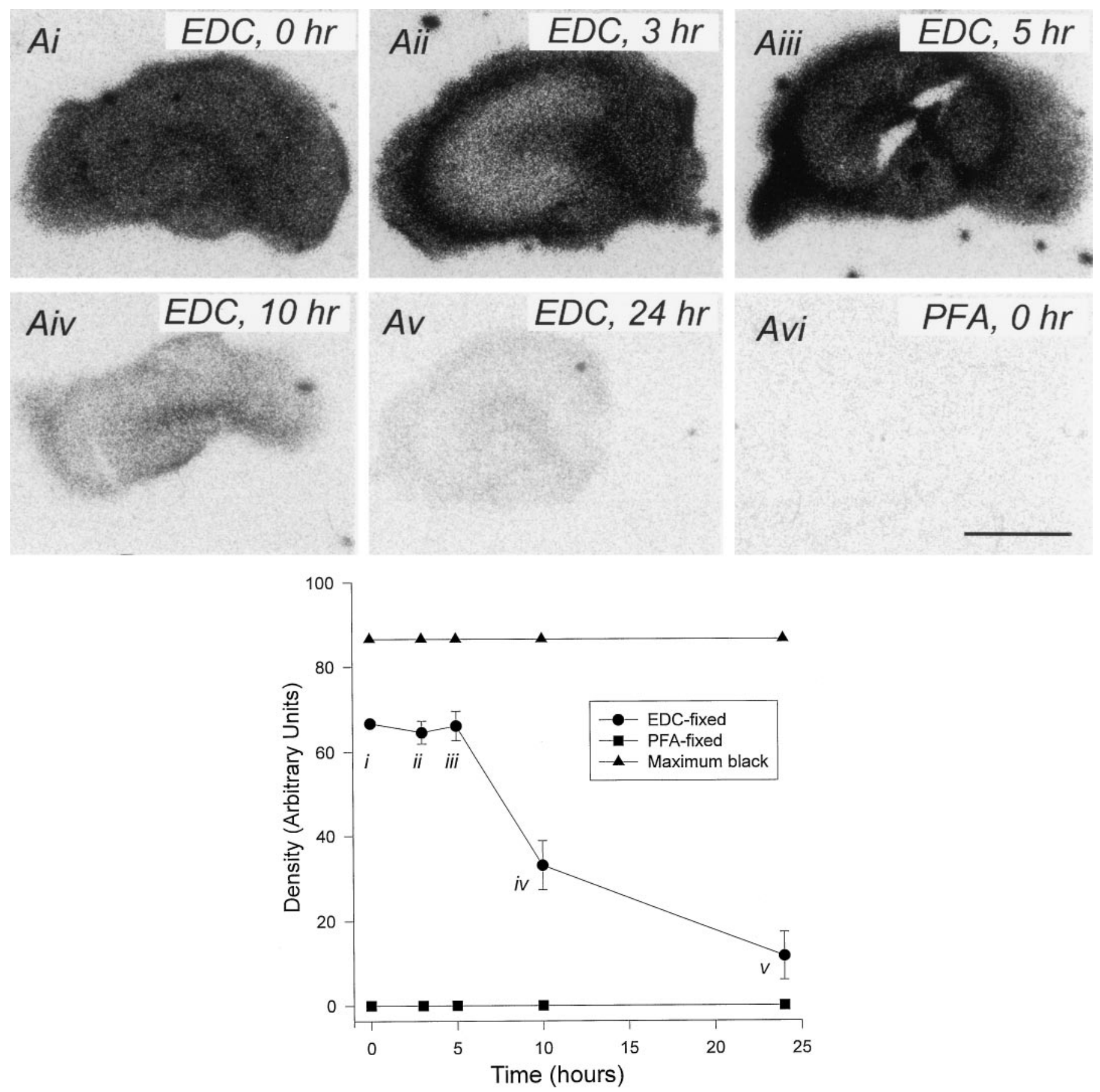

Figure 7. The time course of BAPTA retention in the cultured slices parallels exactly the time course of neuroprotection. The cultures were loaded using ${ }^{14} \mathrm{C}$-BAPTA-AM, and the relative quantity of ${ }^{14} \mathrm{C}$-BAPTA in the slice tissue was assessed autoradiographically. The chelator was fixed at the different times using the cross-linker EDC (see Materials and Methods). $A$, Representative ${ }^{14} \mathrm{C}$-BAPTA autoradiographs of cultures fixed at the indicated times after loading with ${ }^{14} \mathrm{C}$-BAPTA-AM. EDC was used for panels $i-v$. vi illustrates a slice similarly loaded using ${ }^{14} \mathrm{C}$-BAPTA-AM, but fixed in $4 \%$ paraformaldehyde (PFA) rather than with EDC immediately after loading. This fixative fails to maintain the chelator in the tissue (compare with $i$ ). Scale bar, $1.2 \mathrm{~mm}$. $B$, Densitometric quantitation of the time course of BAPTA retention. Data shown are background-subtracted mean density values obtained from at least two ${ }^{14} \mathrm{C}$-BAPTA-AM-loaded slices at each time point and at each group. PFA-fixed slices were not distinguishable from background. The ${ }^{14} \mathrm{C}$-BAPTA signal was retained in the slices for the first $5 \mathrm{hr}$ and then decreased markedly by $24 \mathrm{hr}$ (compare with protective efficacy, Fig. $6 C$ ). The background-corrected maximum black level of the photographic emulsion is also shown (triangles) to emphasize that the complete retention of EDC-fixed slices between 0 and $5 \mathrm{hr}$ is not attributable to a saturation artifact.

\section{DISCUSSION}

Here we examined the hypothesis that enhancing neuronal $\mathrm{Ca}^{2+}$ buffering capacity would attenuate or delay the onset of anoxic neurodegeneration, and we examined the mechanisms of these effects. The toxicity of OGD in the present model of anoxic neurodegeneration (Figs. 1,2) was mediated largely by NMDA receptor activation (Figs. 3, 4). Incubating the cultured slices with BAPTA-AM produced intraneuronal chelator accumulation (Fig. 


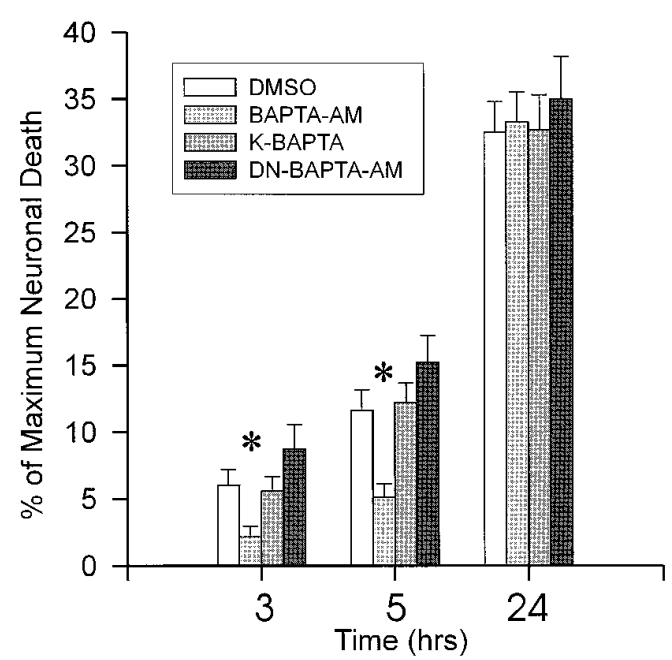

Figure 8. Protection by BAPTA-AM is attributable to intracellular $\mathrm{Ca}^{2+}$ chelation, not to extracellular $\mathrm{Ca}^{2+}$ buffering or to the AM moiety. Slice cultures were challenged with $60 \mathrm{~min}$ OGD in the presence of DMSO alone (DMSO; 24 slices), BAPTA-AM (38 slices), BAPTA tetrapotassium salt (K-BAPTA; 5 slices), which is cell-impermeant, and dinitroBAPTA-AM ( $D N-B A P T A-A M ; 8$ slices), which has a negligible affinity for $\mathrm{Ca}^{2+}$. Asterisks indicate differences from DMSO groups (ANOVA followed by Newman-Keuls procedure for multiple comparisons).

5) and temporarily protected against OGD (Fig. 6). The time course of BAPTA retention in the cultured slices paralleled exactly the time course of neuroprotection (Fig. 7), indicating that enhanced resilience to OGD lasted only while $\mathrm{Ca}^{2+}$ buffering capacity was elevated. This enhanced resilience was attributable to intracellular $\mathrm{Ca}^{2+}$ chelation by BAPTA, and not to extracellular $\mathrm{Ca}^{2+}$ chelation or to the AM moiety (Fig. 8). Furthermore, the site of neuroprotective action of BAPTA was likely presynaptic, because the exogenous $\mathrm{Ca}^{2+}$ buffers were ineffective when the step of transmitter release was bypassed by adding NMDA directly (Fig. 9), and because APTRA-AM, a permeant buffer that selectively attenuates transmitter release, was also effective against OGD (Fig. 10). Although the ability of $\mathrm{Ca}^{2+}$ buffers to attenuate synaptic transmitter release is documented (Adler et al., 1991; Niesen et al., 1991; Tymianski et al., 1994b; Ouanounou et al., 1996; Spigelman et al., 1996), this is the first demonstration that this property underlies the mechanism by which intracellular $\mathrm{Ca}^{2+}$ buffering enhances neuronal resilience against anoxic injury.

Organotypic hippocampal slice cultures are being regarded increasingly as a useful model system for investigating hypoxic/ ischemic mechanisms (Newell et al., 1990, 1995; Vornov and Coyle, 1991; Strassler and Fischer, 1995). We chose this model because, unlike dissociated cell cultures, organotypic slices retain the anatomical integrity of synaptic circuits, which, through synaptic overactivity, may be involved in producing ischemic neuronal damage (Kass and Lipton, 1982; Rothman, 1983, 1984; Johansen et al., 1986; Onodera et al., 1986). Also, the advantages associated with the qualitative and quantitative resemblance of cultured hippocampal slices to mature brain (Gahwiler, 1984; Stoppini et al., 1991; Buchs et al., 1993; Muller et al., 1993) may outweigh potential technical difficulties associated with their use. These difficulties consist primarily of unreliable drug delivery and of uncertainty in quantitatively gauging cell death in the thick tissue slice. However, these issues were overcome in this report (Figs. 1, 2, 5).

Because endogenous cellular $\mathrm{Ca}^{2+}$ buffers are difficult to ma- nipulate, we used the cell-permeant form of BAPTA, an ion chelator that has a high selectivity and affinity for $\mathrm{Ca}^{2+}$ over other ions and that exhibits fast $\mathrm{Ca}^{2+}$ binding (Tsien, 1980; Kao and Tsien, 1988; Pethig et al., 1989). BAPTA, a synthetic buffer, is thought to share several properties with endogenous $\mathrm{Ca}^{2+}$ binding proteins such as calbindin- $\mathrm{D}_{28 \mathrm{~K}}$, including cytoplasmic mobility, $\mathrm{Ca}^{2+}$ affinity, $\mathrm{Ca}^{2+}$ binding rates, and measurable physiological effects (Scharfman and Schwartzkroin, 1989; Chard et al., 1993; Roberts, 1993, 1994). However, unlike endogenous $\mathrm{Ca}^{2+}$ buffers, the loading of BAPTA-like compounds into neurons is reversible, because they are actively extruded from the cell by organic anion transport mechanisms (Di Virgilio et al., 1990; Munsch and Deitmer, 1995; Ouanounou et al., 1996). These features make BAPTA and its analogs ideal for reversibly manipulating cytoplasmic $\mathrm{Ca}^{2+}$ buffering in neurons to directly examine the association between cytoplasmic $\mathrm{Ca}^{2+}$ buffering and neuronal vulnerability to injury.

\section{Time course of neuroprotection from OGD by chelator pretreatment}

The finding that the neuroprotection time course of BAPTA-AM paralleled exactly its retention in the slices suggests the intuitive next step, which is to examine strategies to promote the retention of BAPTA-like buffers in neurons to determine whether this prolongs the protective effect. Because BAPTA and its analogs are primarily extruded by organic anion transport mechanisms (Di Virgilio et al., 1990; Munsch and Deitmer, 1995; Ouanounou et al., 1996), two approaches may be used to enhance chelator retention: (1) using inhibitors of organic anion pumps, such as probenecid, which reduces the extrusion of BAPTA analogs from cells and prolongs the presynaptic inhibition of excitatory neurotransmission (Arkhammar et al., 1991; Ouanounou et al., 1996); and (2) lowering temperature, because membrane transporters function more slowly at reduced temperatures (Bigelow et al., 1986; Sayegh et al., 1992; Knerr and Lieberman, 1993). Both hypothermia (Bruno et al., 1994; Newell et al., 1995) and probenecid (M. Tymianski and R. Sattler, unpublished observations) are inherently neuroprotective in addition to modulating BAPTA retention. Details of their effects on the time course of protection by permeant buffers will be examined in a future report.

\section{Neuroprotection and toxicity of exogenous $\mathrm{Ca}^{2+}$ chelators}

Although enhancing neuronal $\mathrm{Ca}^{2+}$ buffering has neuroprotective potential, we have shown that BAPTA-AM, under select circumstances (moderate insult with NMDA), can also be toxic. This finding reconciles the authors' and others' previously conflicting conclusions about the utility of $\mathrm{Ca}^{2+}$ buffers as neuroprotectants [Scharfman and Schwartzkroin (1989) vs Abdel-Hamid (1994)] (Baimbridge and Abdel-Hamid, 1992; Dubinsky, 1993; Tymianski et al., 1993c, 1994a). For example, Tymianski et al., working in spinal neurons, suggested that pretreatment with BAPTA-AM was protective against a glutamate challenge when toxicity was assayed within a few hours of the insult. However, Abdel-Hamid and Baimbridge showed in hippocampal neurons that pretreatment with BAPTA-AM before excitotoxin application was toxic at $24 \mathrm{hr}$ (see references above). The disparity of previous findings illustrates the importance of evaluating the time course, the mechanism, and the extent of cell death in excitotoxic paradigms, particularly because increasing evidence now suggests that processes mediating excitotoxic neurodegeneration remain operative for many hours beyond the original insult (this paper; Strijbos et 
A

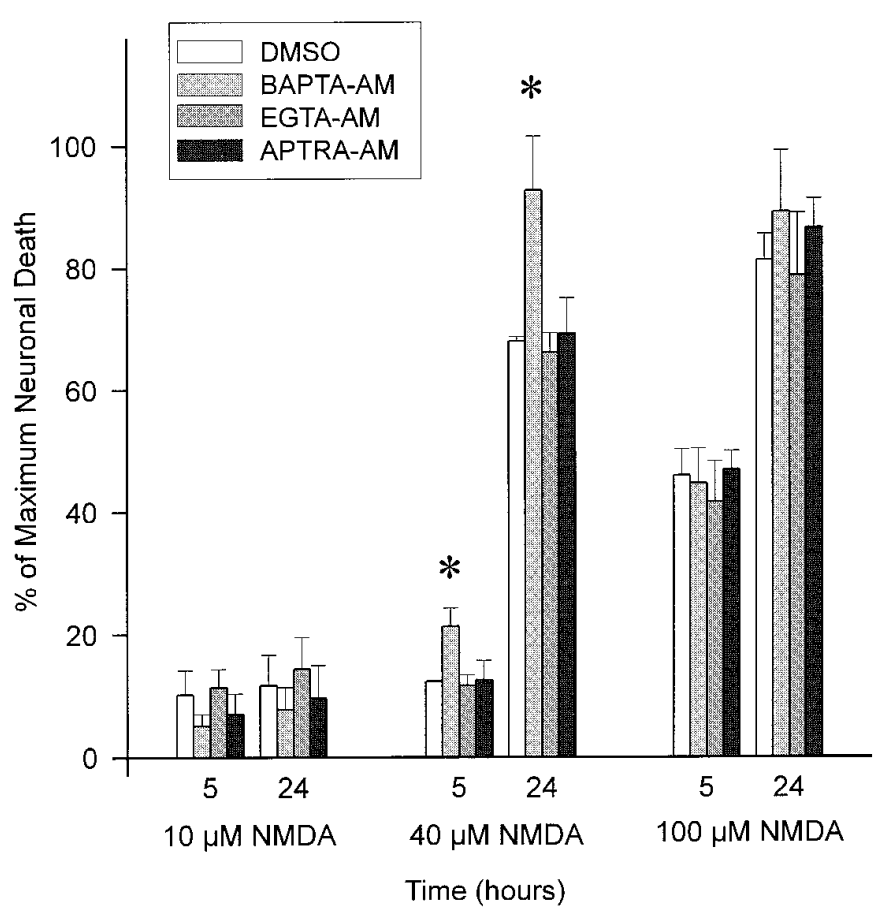

$\mathrm{B}$

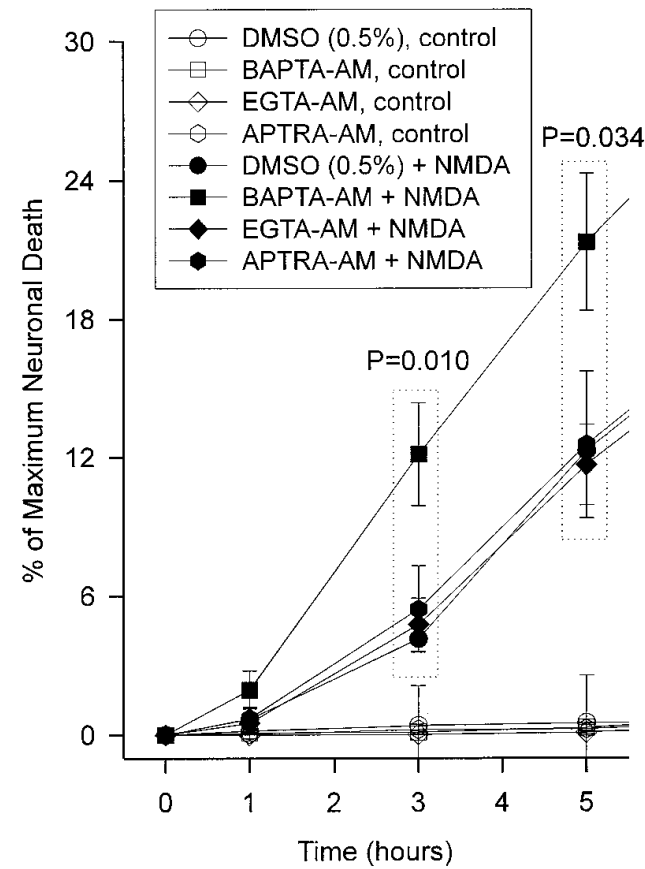

C

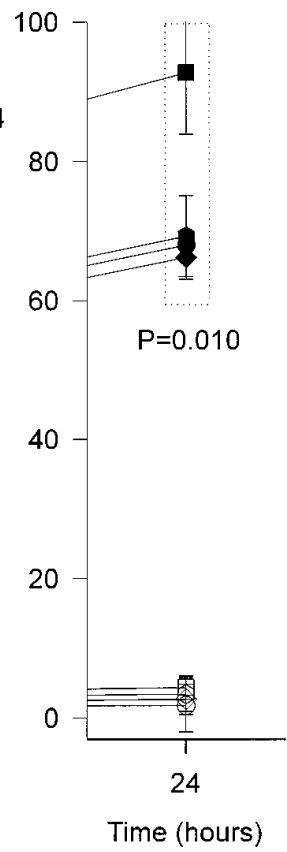

Figure 9. BAPTA-AM pretreatment is ineffective when neurons are directly challenged with NMDA. $A$, Slice cultures were pretreated with $100 \mu \mathrm{M}$ of either BAPTA-AM, EGTA-AM, or APTRA-AM, and were then challenged with either 10, 40, or $100 \mu \mathrm{M}$ NMDA for 60 min (9-11 slices per group). The chelators had no impact on the time course and extent of neurotoxicity produced by the mild and severe NMDA insults (10 and $100 \mu \mathrm{M}$ NMDA, respectively). The intermediate insult (40 $\mu \mathrm{M}$ NMDA) caused increased neurodegeneration in the presence of BAPTA-AM (asterisks, $p<0.05)$. $B, C$, Representative experiments with $40 \mu \mathrm{M}$ NMDA, in which BAPTA-AM, but not EGTA-AM or APTRA-AM, potentiated NMDA toxicity $(n=8-10$ slices in NMDA groups, 4-6 slices in control groups). Dotted boxes, Groups included in ANOVA, followed by Newman-Keuls procedure for multiple comparisons ( $p$ indicates comparisons to BAPTA + NMDA-treated group).

al., 1996). The present report indicates that both previous views have merit, because neuroprotection and toxicity by the chelators may depend both on the mechanism (presynaptic or postsynaptic) and severity of injury.

Previous studies provide limited information on the mechanism of protective action of exogenous $\mathrm{Ca}^{2+}$ buffers. For example, although early protective effects have been reported in cultured spinal neurons after glutamate application (Tymianski et al., 1993c, 1994a), toxicity was not examined at the $24 \mathrm{hr}$ time point, and thus no adverse effects of the chelators were noted. Also, in contrast to the lack of protection seen in BAPTA-AM-treated organotypic hippocampal cultures challenged with NMDA, our work in spinal neurons indicated that treatment of neurons with cell-permeant $\mathrm{Ca}^{2+}$ buffers was protective against the direct application of glutamate. Thus, although the results in the present report point to a principally presynaptic mechanism for the action of the exogenous buffers in hippocampal slice cultures, we cannot rigorously exclude the possibility that, in some instances, the mechanism of neuroprotection by $\mathrm{Ca}^{2+}$ buffers may include a postsynaptic component. A weakness of previous works, however, was that no attempt was made to determine the extent to which endogenous excitotoxin release contributed to toxicity after exogenous glutamate application. Thus, the degree to which attenuation of transmitter release contributed to protection in cultured spinal neurons is uncertain. Similarly, work in vivo in which permeant $\mathrm{Ca}^{2+}$ buffers attenuated neocortical damage in focal brain ischemia (Tymianski et al., 1993c, 1994b) did not specifically rule out either a pre- or postsynaptic locus for the buffers' pro- tective effect. However, in these studies, the demonstration of efficacy of a low-affinity $\mathrm{Ca}^{2+}$ buffer against ischemia (4,4'difluoro BAPTA-AM, $\left.K_{\mathrm{d}} \sim 4600 \mathrm{nM}\right)$ is also suggestive of a presynaptic protective mechanism.

Unlike neuroprotective mechanisms, the physiological effects of exogenous $\mathrm{Ca}^{2+}$ buffers have been better characterized. Buffering of presynaptic $\left[\mathrm{Ca}^{2+}\right]_{\mathrm{i}}$ increases in submembrane regions where transmitter release occurs is a property of fast $\mathrm{Ca}^{2+}$ buffers in the squid giant synapse (Adler et al., 1991), dentate granule cells (Niesen et al., 1991), and CA1 pyramidal neurons (Tymianski et al., 1994b; Ouanounou et al., 1996; Spigelman et al., 1996), and explains the ability of buffers having a wide range of $\mathrm{Ca}^{2+}$ affinities to attenuate transmitter release. Postsynaptically, exogenous $\mathrm{Ca}^{2+}$ buffers affect $\mathrm{Ca}^{2+}$ dynamics (Roberts, 1993, 1994; Zhou and Neher, 1993) and cell membrane excitability by potentiating $\mathrm{Ca}^{2+}$-dependent membrane currents (Zhang et al., 1995). However, the impact of these postsynaptic effects on neuronal vulnerability to injury is uncharacterized.

The mechanisms of toxicity observed in BAPTA-AM-treated cells after a moderate NMDA insult (Fig. 9) are also unclear. Calcium ions are important second messengers governing numerous physiological processes within cells (Blaustein, 1988; Ghosh and Greenberg, 1995). Intuitively therefore, it is understandable that long-standing suppression of physiological $\mathrm{Ca}^{2+}$ signaling in neurons could be harmful. However, the finding that control cultures tolerated being loaded with $\mathrm{Ca}^{2+}$ buffers without exhibiting toxicity (Figs. 6,9) suggests that either toxicity is a synergistic property of neuronal $\mathrm{Ca}^{2+}$ loading in the presence of a buffer, or 
A

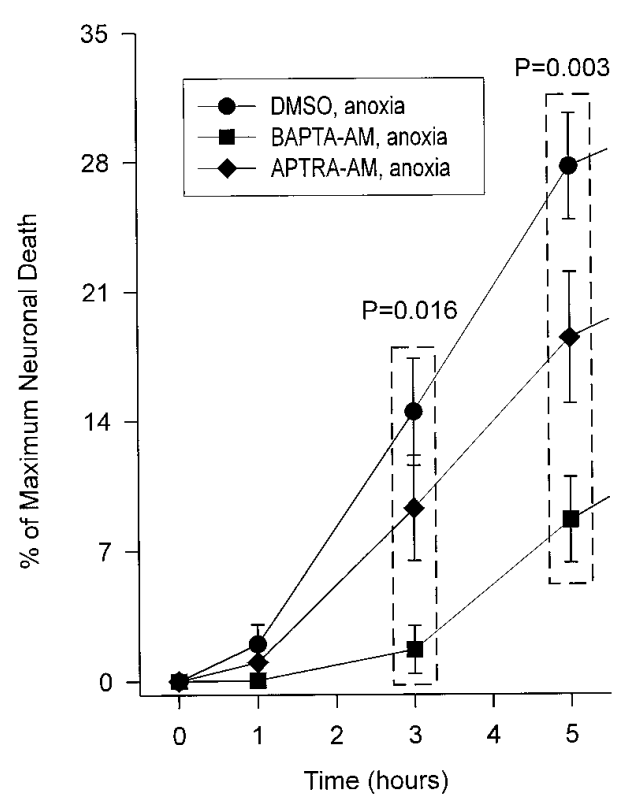

B

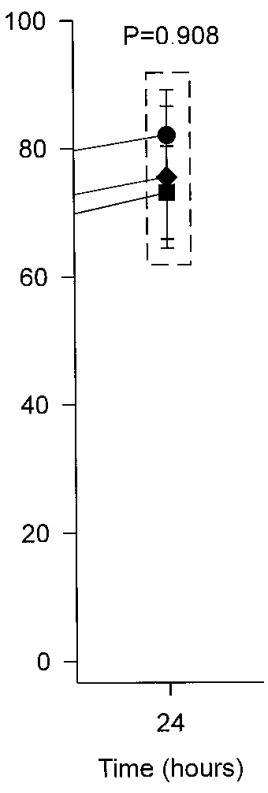

Figure 10. APTRA-AM, a permeant chelator having a lower $\mathrm{Ca}^{2+}$ affinity and different structure from BAPTA-AM, is also effective. Slices were pretreated with $100 \mu \mathrm{M}$ of either BAPTA-AM (11 slices) or APTRA-AM (9 slices). Controls were pretreated with DMSO alone (9 slices). Subsequently, the cultures were exposed to $60 \mathrm{~min}$ OGD. Neuronal survival at 3 and $5 \mathrm{hr}$ after OGD was better in the chelator-treated groups (ANOVA on groups indicated in the dotted boxes was followed by Newman-Keuls procedure for multiple comparisons; $p$ values indicate comparisons to chelator-untreated controls). $A$, Times $0-5 \mathrm{hr}$. B, Outcome at $24 \mathrm{hr}$.

that neurons that are injured by EAAs or by OGD are less tolerant than uninjured controls of the presence of exogenous buffers.

Proponents of the former hypothesis suggest that intracellular $\mathrm{Ca}^{2+}$ chelation may actually increase rather than decrease total neuronal $\mathrm{Ca}^{2+}$ loading (Baimbridge and Abdel-Hamid, 1992; Abdel-Hamid, 1994), thus preventing $\mathrm{Ca}^{2+}$-dependent inactivation of $\mathrm{Ca}^{2+}$ channels or NMDA receptor channels (Legendre et al., 1993). This has been the rationale for using BAPTA as a common ingredient in patch pipette solutions to prevent the rundown of $\mathrm{Ca}^{2+}$ and $\mathrm{Ca}^{2+}$-dependent currents (Spigelman et al., 1992; Zhang et al., 1994, 1995). Certainly, both exogenous BAPTA-like and endogenous $\mathrm{Ca}^{2+}$ buffers have been shown to prolong stimulus-evoked increases in $\left[\mathrm{Ca}^{2+}\right]_{\mathrm{i}}$ in neurons (Chard et al., 1993a; Tymianski et al., 1994a). Thus, although this has never been tested directly, the toxicity of enhanced $\mathrm{Ca}^{2+}$ buffering could be directly attributable to increased postsynaptic $\mathrm{Ca}^{2+}$ loading (Hartley et al., 1993; Lu et al., 1996). Interestingly, transfecting $\mathrm{GH} 3$ cells with calbindin- $\mathrm{D}_{28 \mathrm{~K}}$ caused a decrease rather than an increase in stimulus-evoked calcium currents (Lledo et al., 1992), and decreasing the ability of mitochondria to buffer $\mathrm{Ca}^{2+}$ in cerebellar granule cells decreased neuronal $\mathrm{Ca}^{2+}$ loading and consequent neurotoxicity (Budd and Nicholls, 1996b). Both findings are contradictory to the notion that enhanced $\mathrm{Ca}^{2+}$ buffering increases $\mathrm{Ca}^{2+}$ loading. Pending direct examination of the above hypothesis, an additional possibility is that BAPTA-AM toxicity is unrelated to $\mathrm{Ca}^{2+}$ chelation. For example, after deesterification, the metabolism of AM moieties to formaldehyde (Tsien, 1981) may be toxic when excessive quantities of BAPTA-AM are used. This could explain why toxic effects of BAPTA-AM persisted after
BAPTA itself was extruded from the cells (Fig. 7). Also, BAPTA and its analogs have been shown to pharmacologically block inositol triphosphate-mediated $\mathrm{Ca}^{2+}$ release and the activation of phospholipases independently of $\mathrm{Ca}^{2+}$ chelation (Coorssen and Haslam, 1993; Richardson and Taylor, 1993). Finally, toxicity could be ascribed to a combination of the above possibilities.

\section{Conclusion}

The present results demonstrate for the first time that enhancing the $\mathrm{Ca}^{2+}$ buffering capacity of cultured neurons can delay or attenuate the onset of anoxic neurodegeneration, most likely by presynaptic inhibition of excitatory neurotransmitter release. However, exogenous permeant $\mathrm{Ca}^{2+}$ chelators such as BAPTA-AM may be less effective when the injury does not involve endogenous synaptic overactivity, and may exhibit toxicity. Further work is warranted to better define the protective and toxic sequelae of $\mathrm{Ca}^{2+}$ buffering in neurons, because this previously understudied aspect of cellular $\mathrm{Ca}^{2+}$ regulation may provide useful new approaches to treating neurodegenerative disorders associated with disturbed $\mathrm{Ca}^{2+}$ homeostasis.

\section{REFERENCES}

Abdel-Hamid KM (1994) The regulation of intracellular calcium in cultured hippocampal neurons and the influence of calcium buffers. PhD thesis, University of British Columbia.

Adler EM, Augustine GJ, Duffy SN, Charlton MP (1991) Alien intracellular calcium chelators attenuate neurotransmitter release at the squid giant synapse. J Neurosci 11:1496-1507.

Arkhammar P, Nilsson T, Bergmann PO (1991) Glucose mediated efflux of indo- 1 from pancreatic B-cells is reduced by probenecid. FEBS Lett 273:182-184.

Baimbridge KG, Abdel-Hamid KM (1992) Intra-neuronal $\mathrm{Ca}^{2+}$. buffering with BAPTA enhances glutamate excitotoxicity in vitro and ischemic damage in vivo. Soc Neurosci Abstr 18:571.4.

Bigelow DJ, Squier TC, Thomas DD (1986) Temperature dependence of rotational dynamics of protein and lipid in sarcoplasmic reticulum membranes. Biochemistry 25:194-202.

Blaustein MP (1988) Calcium transport and buffering in neurons. Trends Neurosci 11:438-443.

Bruno VM, Goldberg MP, Dugan LL, Giffard RG, Choi DW (1994) Neuroprotective effect of hypothermia in cortical cultures exposed to oxygen-glucose deprivation or excitatory amino acids. J Neurochem 63:1398-1406.

Buchs PA, Stoppini L, Muller D (1993) Structural modifications associated with synaptic development in area CA1 of rat hippocampal organotypic cultures. Dev Brain Res 71:81-91.

Budd SL, Nicholls DG (1996a) A reevaluation of the role of mitochondria in neuronal $\mathrm{Ca}^{2+}$ homeostasis. J Neurochem 66:403-411.

Budd SL, Nicholls DG (1996b) Mitochondria, calcium regulation, and acute glutamate excitotoxicity in cultured cerebellar granule cells. J Neurochem 67:2282-2291.

Chard PS, Bleakman D, Christakos S, Fullmer CS, Miller RJ (1993) Calcium buffering properties of calbindin $\mathrm{D}_{28 \mathrm{k}}$ and parvalbumin in rat sensory neurones. J Physiol (Lond) 472:341-357.

Choi DW (1988) Calcium-mediated neurotoxicity: relationship to specific channel types and role in ischemic damage. Trends Neurosci 11:465-467.

Coorssen JR, Haslam RJ (1993) GTP $\gamma \mathrm{S}$ and phorbol ester act synergistically to stimulate both $\mathrm{Ca}^{2+}$-independent secretion and phospholipase D activity in permeabilized human platelets. FEBS Lett 316:170-174.

Dani JW, Chernjavsky A, Smith SJ (1992) Neuronal activity triggers calcium waves in hippocampal astrocytic networks. Neuron 8:429-440.

David JC, Yamada KA, Bagwe MR, Goldberg MP (1996) AMPA receptor activation is rapidly toxic to cortical astrocytes when desensitization is blocked. J Neurosci 16:200-209.

Di Virgilio F, Steinberg TH, Silverstein SC (1990) Inhibition of fura-2 sequestration and secretion with organic anion transport blockers. Cell Calcium 11:57-62.

Diop AG, Lesort M, Esclaire F, Dumas M, Hugon J (1995) Calbindin $\mathrm{D}_{28 \mathrm{~K}}$-containing neurons, and not HSP70-expressing neurons, are more 
resistant to HIV-1 envelope (gp120) toxicity in cortical cell cultures. J Neurosci Res 42:252-258.

Dubinsky JM (1993) Effects of calcium chelators on intracellular calcium and excitotoxicity. Neurosci Lett 150:129-132.

Fredholm BB, Hu PS (1993) Effect of an intracellular calcium chelator in the regulation of electrically evoked $\left[{ }^{3} \mathrm{H}\right]$-noradrenaline release from rat hippocampal slices. Br J Pharmacol 108:126-131.

Freund TF, Magloczky Z (1993) Early degeneration of calretinincontaining neurons in the rat hippocampus after ischemia. Neuroscience 56:581-596.

Freund TF, Buzsaki G, Leon A, Baimbridge KG, Somogyi P (1990) Relationship of neuronal vulnerability and calcium binding protein immunoreactivity in ischemia. Exp Brain Res 83:55-66.

Gahwiler BH (1984) Development of the hippocampus in vitro: cell types, synapses and receptors. Neuroscience 4:751-760.

Ghosh A, Greenberg ME (1995) Calcium signalling in neurons: molecular mechanisms and cellular consequences. Science 268:239-247.

Goodman JH, Wasterlain CG, Massarweh WF, Dean E, Sollas AL, Sloviter RS (1993) Calbindin- $\mathrm{D}_{28 \mathrm{~K}}$ immunoreactivity and selective vulnerability to ischemia in the dentate gyrus of the developing rat. Brain Res 606:309-314.

Hartley DM, Kurth MC, Bjerkness L, Weiss JH, Choi DW (1993) Glutamate receptor-induced ${ }^{45} \mathrm{Ca}^{2+}$ accumulation in cortical cell culture correlates with subsequent neuronal degeneration. J Neurosci 13:1993-2000.

Johansen FF, Jorgensen MB, Diemer NH (1986) Ischemic CA1 pyramidal cell loss is prevented by preischemic colchicine destruction of dentate granule cells. Brain Res 377:344-347.

Kao JPY, Tsien RY (1988) $\mathrm{Ca}^{2+}$ binding kinetics of fura-2 and azo-1 from temperature-jump relaxation measurements. Biophys J 53:635-639.

Kass IS, Lipton P (1982) Mechanisms involved in irreversible anoxic damage to the in vitro rat hippocampal slice. J Physiol (Lond) 332:459-472.

Kass IS, Lipton P (1986) Calcium and long-term transmission damage following anoxia in dentate gyrus and CA1 regions of rat hippocampal slice. J Physiol (Lond) 378:313-334.

Kendall PA, Polak JM, Pearse AGE (1971) Carbodiimide fixation for immunohistochemistry: observations on the fixation of polypeptide hormones. Experientia 27:1104-1106.

Knerr SM, Lieberman M (1993) Ion transport during hypothermia in cultured heart cells: implications for protection of the immature myocardium. J Mol Cell Cardiol 25:277-288.

Koh JY, Choi DW (1987) Quantitative determination of glutamate mediated cortical neuronal injury in cell culture by lactate dehydrogenase efflux assay. J Neurosci Methods 20:83-90.

Kohr G, Mody I (1991) Endogenous intracellular calcium buffering and the activation/inactivation of HVA calcium currents in rat dentate gyrus granule cells. J Gen Physiol 98:941-967.

Lancaster B, Nicoll RA (1987) Properties of two calcium-activated hyperpolarizations in rat hippocampal neurones. J Physiol (Lond) 389:187-203.

Legendre P, Rosenmund C, Westbrook GL (1993) Inactivation of NMDA channels in cultured hippocampal neurons by intracellular calcium. J Neurosci 13:674-684.

Lledo PM, Somasundram B, Morton AJ, Emson PC, Mason WT (1992) Stable transfection of calbindin- $\mathrm{D}_{28 \mathrm{k}}$ into the $\mathrm{GH} 3$ cell line alters calcium currents and intracellular calcium homeostasis. Neuron 9:943-954.

Lu YM, Yin HZ, Chiang J, Weiss JH (1996) $\mathrm{Ca}^{2+}$-permeable AMPA/ kainate and NMDA channels: high rate of $\mathrm{Ca}^{2+}$ influx underlies potent induction of injury. J Neurosci 16:5457-5465.

Lukas W, Jones KA (1994) Cortical neurons containing calretinin are selectively resistant to calcium overload and excitotoxicity in vitro. Neuroscience 61:307-316.

Marty A, Neher E (1985) Potassium channels in cultured bovine adrenal chromaffin cells. J Physiol 367:117-141.

Mattson MP, Rychlik B, Chu C, Christakos S (1991) Evidence for calcium-reducing and excito-protective roles for the calcium-binding protein calbindin- $\mathrm{D}_{28 \mathrm{k}}$ in cultured hippocampal neurons. Neuron 6:41-51.

Mockel V, Fischer G (1994) Vulnerability to excitotoxic stimuli of cultured rat hippocampal neurons containing the calcium-binding proteins calretinin and calbindin $\mathrm{D}_{28 \mathrm{~K}}$. Brain Res 648:109-120.
Muller D, Buchs PA, Stoppini L (1993) Time course of synaptic development in hippocampal organotypic cultures. Dev Brain Res 71:93-100.

Munsch T, Deitmer JW (1995) Maintenance of fura-2 fluorescence in glial cells and neurones of the leech central nervous system. J Neurosci Methods 57:195-204.

Neher E (1986) Concentration profiles of intracellular calcium in the presence of a diffusible chelator. In: Calcium electrogenesis and neuronal functioning (Heinemann U, Klee M, Neher E, eds), pp 80-96. Berlin-Heidelberg: Springer.

Neher E, Augustine GJ (1992) Calcium gradients and buffers on bovine chromaffin cells. J Physiol (Lond) 450:273-301.

Newell DW, Malouf AT, Franck JE (1990) Glutamate-mediated selective vulnerability to ischemia is present in organotypic cultures of hippocampus. Neurosci Lett 116:325-330.

Newell DW, Barth A, Papermaster V, Malouf AT (1995) Glutamate and non-glutamate receptor mediated toxicity caused by oxygen and glucose-deprivation in organotypic hippocampal cultures. J Neurosci 15:7702-7711.

Niesen C, Charlton MP, Carlen PL (1991) Postsynaptic and presynaptic effects of the calcium chelator BAPTA on synaptic transmission in rat hippocampal dentate granule neurons. Brain Res 555:319-325.

Nitsch C, Scotti A, Sommacal A, Kalt G (1989) GABAergic hippocampal neurons resistant to ischemia-induced neuronal death contain the Ca2(+)-binding protein parvalbumin. Neurosci Lett 105:263-268.

Novelli A, Reilly JA, Lysko PG, Henneberry RC (1988) Glutamate becomes neurotoxic via the $N$-methyl-D-aspartate receptor when intracellular energy levels are reduced. Brain Res 451:205-212.

Onodera H, Sato G, Kogure K (1986) Lesions in Schaffer collaterals prevent ischemic death in CA1 pyramidal cells. Neurosci Lett 68:169-174.

Ouanounou A, Zhang L, Tymianski M, Charlton MP, Wallace MC, Carlen PL (1996) Accumulation and extrusion of permeant $\mathrm{Ca}^{2+}$ chelators in attenuation of synaptic transmission at hippocampal CA1 neurons. Neuroscience 75:99-109.

Pethig RR, Kuhn M, Payne R, Adler EM, Chen TH, Jaffe JH (1989) On the dissociation constants of BAPTA-type calcium buffers. Cell Calcium 10:491-498.

Pike CJ, Cotman CW (1995) Calretinin-immunoreactive neurons are resistant to beta-amyloid toxicity in vitro. Brain Res 671:293-298.

Rami A, Rabie A, Thomasset M, Krieglstein J (1992) Calbindin- $\mathrm{D}_{28 \mathrm{~K}}$ and ischemic damage of pyramidal cells in rat hippocampus. J Neurosci Res 31:89-95.

Richardson A, Taylor CW (1993) Effects of $\mathrm{Ca}^{2+}$ chelators on purified inositol 1,4,5-triphosphate (InsP3) receptors and InsP3-stimulated $\mathrm{Ca}^{2+}$ mobilization. J Biol Chem 268:11528-11533.

Roberts WM (1993) Spatial calcium buffering in saccular hair cells. Nature 363:74-76.

Roberts WM (1994) Localization of calcium signals by a mobile calcium buffer in frog saccular hair cells. J Neurosci 15:3246-3262.

Robitaille R, Garcia ML, Kaczorowski GJ, Charlton MP (1993) Functional colocalization of calcium and calcium-gated potassium channels in control of transmitter release. Neuron 11:645-655.

Rosenberg PA (1991) Accumulation of extracellular glutamate and neuronal death in astrocyte-poor cortical cultures exposed to glutamine. Glia 4:91-100.

Rothman SM (1983) Synaptic activity mediates death of hypoxic neurons. Science 220:536-537.

Rothman SM (1984) Synaptic release of excitatory amino acid neurotransmitter mediates anoxic neuronal death. J Neurosci 4:1884-1891.

Sattler R, Charlton MP, Hafner M, Tymianski M (1997) Determination of the time-course and extent of neurotoxicity at defined temperatures in cultured neurons using a modified multi-well plate fluorescence scanner. J Cereb Blood Flow Metab, in press.

Sayegh JF, Sershen H, Lajtha A (1992) Different effects of hypothermia on amino acid incorporation and on amino acid uptake in the brain in vivo. Neurochem Res 17:553-557.

Scharfman HE, Schwartzkroin PA (1989) Protection of dentate hilar cells from prolonged stimulation by intracellular calcium chelation. Science 246:257-260.

Schindler AF, Olson EC, Spitzer NC, Montal M (1996) Mitochondrial dysfunction is a primary event in glutamate neurotoxicity. J Neurosci 16:6125-6133.

Schwindt PC, Spain WJ, Crill WE (1992) Effects of intracellular calcium chelation on voltage-dependent and calcium-dependent currents in cat neocortical neurons. Neuroscience 47:571-578. 
Smith SJ, Augustine GJ (1988) Calcium ions, active zones, and synaptic transmitter release. Trends Neurosci 11:458-464.

Spigelman I, Zhang L, Carlen PL (1992) Patch-clamp study of postnatal development of CA1 neurons in rat hippocampal slices: membrane excitability and $\mathrm{K}^{+}$currents. J Neurophysiol 68:55-69.

Spigelman I, Tymianski M, Wallace MC, Carlen PL, Velumian AA (1996) Modulation of hippocampal synaptic transmission by low concentrations of cell-permeant calcium chelators: effects of calcium affinity, structure, and binding kinetics. Neuroscience 75:559-572.

Stoppini L, Buchs PA, Muller D (1991) A simple method for organotypic cultures of nervous tissue. J Neurosci Methods 37:173-182.

Strassler U, Fischer G (1995) Quantitative measurement of neuronal degeneration in organotypic hippocampal cultures after combined oxygen/glucose deprivation. J Neurosci Methods 57:177-186.

Strijbos PJLM, Leach MJ, Garthwaite J (1996) Vicious cycle involving $\mathrm{Na}^{+}$channels, glutamate release, and NMDA receptors mediates delayed neurodegeneration through nitric oxide formation. J Neurosci 16:5004-5013.

Tortosa A, Ferrer I (1994) Poor correlation between delayed neuronal death induced by transient forebrain ischemia, and immunoreactivity for parvalbumin and calbindin $\mathrm{D}_{28 \mathrm{k}}$ in developing gerbil hippocampus. Acta Neuropathol (Berl) 88:67-74.

Tsien RY (1980) New calcium indicators and buffers with high selectivity against magnesium and protons: design, synthesis, and properties of prototype structures. Biochemistry 19:2396.

Tsien RY (1981) A non-disruptive technique for loading calcium buffers and indicators into cells. Nature 290:527-528.

Tymianski M (1996) Cytosolic calcium concentrations and cell death in vitro. In: Advances in neurology: cellular and molecular mechanisms of ischemic brain damage (Siesjo BK, Wieloch T, eds), pp 85-105. Philadelphia: Lippincott-Raven.

Tymianski M, Tator CH (1996) Normal and abnormal calcium homeostasis in neurons: a basis for the pathophysiology of traumatic and ischemic central nervous system injury. Neurosurgery 38:1176-1195.

Tymianski M, Charlton MP, Carlen PL, Tator CH (1993a) Source specificity of early calcium neurotoxicity in cultured embryonic spinal neurons. J Neurosci 13:2085-2104.

Tymianski M, Charlton MP, Carlen PL, Tator CH (1993b) Secondary $\mathrm{Ca}^{2+}$ overload indicates early neuronal injury which precedes staining with viability indicators. Brain Res 607:319-323.

Tymianski M, Wallace MC, Spigelman I, Uno M, Carlen PL, Tator CH, Charlton MP (1993c) Cell permeant $\mathrm{Ca}^{2+}$ chelators reduce early excitotoxic and ischemic neuronal injury in vitro and in vivo. Neuron 11:221-235.

Tymianski M, Charlton MP, Carlen PL, Tator CH (1994a) Properties of neuroprotective cell-permeant $\mathrm{Ca}^{2+}$ chelators: effects on $\left[\mathrm{Ca}^{2+}\right]_{\mathrm{i}}$ and glutamate neurotoxicity in vitro. J Neurophysiol 267:1973-1992.

Tymianski M, Spigelman I, Zhang L, Carlen PL, Tator CH, Charlton MP,
Wallace MC (1994b) Mechanism of action and persistence of neuroprotection by cell permeant $\mathrm{Ca}^{2+}$ chelators. J Cereb Blood Flow Metab 14:911-923.

Tymianski M, Bernstein GM, Abdel-Hamid KM, Sattler R, Velumian A, Carlen PL, Razavi H, Jones OT (1997) A novel use for a carbodiimide compound for the fixation of fluorescent and non-fluorescent calcium indicators in-situ following physiological experiments. Cell Calcium, in press.

Van Der Zee J, Mason RP, Eling TE (1989) The oxidation of the calcium probe Quin2 and its analogs by prostaglandin H synthase. Arch Biochem Biophys 271:1-64.

Vibulsreth S, Hefti F, Ginsberg MD, Dietrich WD, Busto R (1987) Astrocytes protect cultured neurons from degeneration induced by anoxia. Brain Res 422:303-311.

Vornov JJ, Coyle JT (1991) Enhancement of NMDA receptor-mediated neurotoxicity in the hippocampal slice by depolarization and ischemia. Brain Res 555:99-106.

Weiss JH, Koh JY, Baimbridge KG, Choi DW (1990) Cortical neurons containing somatostatin- or parvalbumin-like immunoreactivity are atypically vulnerable to excitotoxic injury in vitro. Neurology 40:1288-1292.

Werth JL, Thayer SA (1994) Mitochondria buffer physiological calcium loads in cultured rat dorsal root ganglion neurons. J Neurosci 14:348-356.

White RJ, Reynolds IJ (1995) Mitochondria and $\mathrm{Na}^{+} / \mathrm{Ca}^{2+}$ exchange buffer glutamate-induced calcium loads in cultured cortical neurons. J Neurosci 15:1318-1328.

Winslow JL, Duffy SN, Charlton MP (1994) Homosynaptic facilitation of transmitter release in crayfish is not affected by mobile calcium chelators: implications for the residual ionized calcium hypothesis from electrophysiological and computational analyses. J Neurophysiol 72:1769-1793.

Yamamoto N, Yasuda K (1977) Use of a water soluble carbodiimide as a fixing agent. Acta Histochem Cytochem 10:14-37.

Yuste R, Katz LC (1991) Control of postsynaptic $\mathrm{Ca}^{2+}$ influx in developing neocortex by excitatory and inhibitory neurotransmitters. Neuron 6:333-344.

Zhang L, Weiner JL, Valiante TA, Velumian AA, Watson PL, Jahromi SS, Schertzer S, Pennefather P, Carlen PL (1994) Whole-cell recording of the $\mathrm{Ca}^{2+}$-dependent slow afterhyperpolarization in hippocampal neurones: effects of internally applied anions. Pflügers Arch 426:247-253.

Zhang L, Pennefather P, Velumian A, Tymianski M, Charlton M, Carlen PL (1995) Potentiation of a slow $\mathrm{Ca}^{2+}$-dependent $\mathrm{K}^{+}$current by intracellular $\mathrm{Ca}^{2+}$ chelators in hippocampal CA1 neurons of rat brain slices. J Neurophysiol 74:2225-2241.

Zhou Z, Neher E (1993) Mobile and immobile calcium buffers in bovine adrenal chromaffin cells. J Physiol (Lond) 469:245-273. 